Title: Core Design Optimization and Analysis of the Purdue Novel Modular Reactor (NMR-50)

Authors: Faisal Y. Odeh and Won Sik Yang ${ }^{*}$

Affiliation: Department of Nuclear Engineering, Purdue University, IN 47907, USA

Corresponding author: Won Sik Yang

E-mail address: yang494@purdue.edu

Telephone: (765) 494-4710

Mailing address: 400 Central Dr., West Lafayette, IN 47907, USA

Total Number of Pages: $\quad 37$ (including this page)

Number of Tables: $\quad 7$

Number of Figures: $\quad 17$ 


\title{
Core Design Optimization and Analysis of the Purdue Novel Modular Reactor (NMR-50)
}

\author{
Faisal Odeh and Won Sik Yang
}

\begin{abstract}
A BWR-based SMR called the Novel Modular Reactor (NMR-50) is being developed at Purdue University. NMR takes the advantages of the two-phase flow driving head, which allows a much smaller and simpler reactor pressure vessel (RPV) compared to the integral PWRs. In this study, through a systematic step-wise optimization approach including a simulated annealing based optimization method, an optimum core design that meets a 10-year cycle length with a minimum fuel cost while satisfying safety related criteria was derived and analyzed. The lattice code CASMO-4, the whole core analysis code PARCS and the thermal-hydraulics code RELAP5 were used to perform calculations from pin cell up to whole core depletion calculations. The NMR-50 optimized core design is able to achieve a 10.2 year cycle length with an average fuel enrichment of $4.61 \mathrm{wt} \%$ of ${ }^{235} \mathrm{U}$ in a $10 \times 10$ lattice fuel assembly. The minimum critical power ratio (MCPR) and the maximum fuel linear power density (MFLPD) during the cycle are 1.99 and $18.25 \mathrm{~kW} / \mathrm{m}$, respectively, providing large margins to thermal design constraints. The NMR50 control system design is able to provide a sufficient cold shutdown margin of $1.7 \%$. With its small reactor core size, large negative void coefficient, and low operating thermal neutron flux, an enhanced xenon stability characteristic is possible. Peak fast neutron fluence of $8.8 \times 10^{21} \mathrm{n} / \mathrm{cm}^{2}$ was below the industry standard limit, which from extensive plant data records, should not be a major concern to channel distortions from a radiation damage point of view.
\end{abstract}

\section{Keywords}

Core Design Optimization

Long-life Core

Simulated Annealing

Novel Modular Reactor

BWR 


\section{Abbreviations}

$\begin{array}{ll}\text { SMR } & \text { Small Modular Reactor } \\ \text { NMR } & \text { Novel Modular Reactor } \\ \text { BOC } & \text { Beginning of Cycle } \\ \text { EOC } & \text { End of Cycle } \\ \text { VC } & \text { Void Coefficient } \\ \text { MCPR } & \text { Minimum Critical Power Ratio } \\ \text { MFLPD } & \text { Maximum Fuel Linear Power Density } \\ \text { SDM } & \text { Shutdown Margin } \\ \text { PMAXS } & \text { Purdue Macroscopic Cross-Section } \\ \text { S3C } & \text { SIMULATE-3 Case Matrix } \\ \text { CHF } & \text { Critical Heat Flux } \\ \text { BP } & \text { Burnable Poison } \\ \text { Gd } & \text { Gadolinium } \\ \text { SA } & \text { Simulated Annealing } \\ \text { FA } & \text { Fuel Assembly } \\ \text { AO } & \text { Axial Offset } \\ \text { O-2 } & \text { Oskarshamn-2 }\end{array}$




\section{Introduction}

Since the establishment of nuclear power generation for commercial use, reactor size had been consistently increasing from 60 MWe to around 1600 MWe (IAEA, 2012). In recent years, there has been an increase in interest in small modular reactors (SMRs), below $300 \mathrm{MWe}$, due to the significant capital cost reduction, simpler design units, reduced construction time, and power accessibility to regions away from large grid systems. SMR has a market that includes countries with moderate sized grid system, many islands, and remote islands as well as countries planning to fine tune the electricity generation capacity. The United States, Argentina, Brazil, France, Japan, Republic of Korea, and Russia are one of the countries with ongoing interest and development of SMRs (IAEA, 2012). In terms of nuclear design principles, SMRs are not a foreigner to current large LWR's. In fact, it is based upon extensive nuclear operational experience of current LWR's (Worrall, 2015).

By taking the advantages of the two-phase flow driving head, which allows a much smaller and simpler reactor pressure vessel compared to the integral PWRs, a BWR-based SMR called the Novel Modular Reactor (NMR) is currently being developed at Purdue University. The NMR system design was derived from the 600 MWe simplified boiling water reactor (SBWR-600) design of General Electric (GE) based on a three-level scaling methodology (Ishii et al., 2013). The NMR has a significantly reduced reactor pressure vessel height. Precisely, its height is reduced by a factor of three compared to conventional BWR RPVs and has a net electrical power output of $50 \mathrm{MWe}$.

The key objective of the NMR-50 core design is to be able to achieve a 10-year cycle length for the deployment in remote sites while satisfying thermal-hydraulics and materials related design criteria (Wu et al., 2015). Wu et al. (2015) developed a core design that meets these design objective and constraints through parametric studies starting from the AREVA Atrium 10B assembly design. In this work, a systematic step-by-step optimization approach, including a simulated annealing (SA) based optimization method (Kirkpatrick et al., 1983) was performed to deliver an optimum core design that meets these design goals with a minimum fuel cost.

This paper is structured as follows: in Section 2, the design objectives, constraints, and main variables are presented. Section 3 describes the neutronics and thermal-hydraulics analysis methods and models, and Section 4 presents the systematic step-wise optimization approach, tools used, and the results obtained. In Section 5, the NMR-50 design and performance characteristics are discussed. Section 6 discusses the main conclusions. 


\section{Design objectives and constraints}

The main design objective of the NMR-50 is to obtain a cycle length of 10 years while minimizing the fissile loading (i.e., fuel cost). The current commercial BWR operates at a maximum specific power of around $24 \mathrm{~W} / \mathrm{gU}$. However, at this specific power level, it is not possible to achieve a cycle length of 10 years under the current industrial constraint of $5 \mathrm{wt} \%$ fuel enrichment. Therefore, it is necessary to reduce the specific power to achieve the targeted 10 -year cycle length.

To ensure safe plant operation, two types of design constraints were imposed: reactivity bases and overpower bases. One of the main reactivity constraints on the core design is to ensure negative reactivity feedback coefficients. For a low enriched uranium fuel, the fuel temperature coefficient of reactivity is negative mainly due to the Doppler effects of U-238 resonance cross sections. In BWRs, voiding is the predominant factor in moderator density changes. Since a large coolant void coefficient (VC) can lead to an excessive power tilting, the minimum VC was constrained to be around $-50 \mathrm{pcm} / \%$ void at beginning of cycle (BOC) to limit the power tilting while providing a sufficient negative reactivity feedback. In addition, the cold shutdown margin (SDM) was required to be greater than $1 \%$. As the overpower-based constraints, the minimum critical power ratio (MCPR) and the maximum fuel linear power density (MFLPD) were considered. The MCPR characterizes the "flow boiling crisis" phenomenon, in a two-phase fluid flow, which is strictly prohibited in the operation of BWRs. The MFLPD limits the peak cladding temperature during a loss of coolant accident (LOCA). The limiting values of the GE SBWR-600 were adopted in this study, which are 1.3 and $45.3 \mathrm{~kW} / \mathrm{m}$ for the MCPR and MFLPD, respectively (Ishii et al., 2013).

Another constraint in the design of NMR-50 takes into account the effect of a 10-year cycle length on the performance and integrity of structural material. Since irradiation damage strongly depends on fast neutron fluence, the peak fast fluence was limited to the current BWR standard. Typical operational peak condition of structural components, such as the fuel assembly (FA) channel box, is $2 \times 10^{22} \mathrm{n} / \mathrm{cm}^{2}$ (Bradley and Sabol, 1996).

These design objectives and constraints are shown in Table 1 along with the design variables considered. The core design variables in Table 1 are divided into two groups, main and other variables. Since NMR-50 was derived from SBWR-600, large fractions of the design variables are fixed such as the core radius, number of assemblies, fuel height, etc. As a result, the primary core design parameters that significantly affect the core performance are those included in the "main variables." 
Table 1

Design objectives, constraints, and variables of NMR-50 core.

\begin{tabular}{ll}
\hline Parameter & Value \\
\hline Core design objectives & $\geq 10$ years \\
Cycle length & Minimize \\
Fuel cost & \\
Core design constraints & $5 \mathrm{wt} \%$ \\
Maximum fuel enrichment of U-235 & $>1.3$ \\
Minimum critical power ratio & $<45 \mathrm{~kW} / \mathrm{m}$ \\
Maximum fuel linear power density & $<2 \times 10^{22} \mathrm{n} / \mathrm{cm}^{2}$ \\
Fast neutron fluence (E $>1 \mathrm{MeV})$ & Negative \\
Reactivity coefficients & $<-50 \mathrm{pcm} / \%$ void \\
Void coefficient at BOC & $\geq 1 \% \Delta \rho($ Oka, 2010) \\
Sufficient shutdown margin of control system & \\
Core design variable & Other variables \\
Main variables & Active fuel height \\
Fuel enrichment & Clad thickness \\
Fuel rod diameter & Core radius \\
Water-to-fuel volume ratio & Gap thickness \\
& Number of control blades \\
& Assembly size \\
\hline
\end{tabular}




\section{Analysis methods and models}

In this section, the analysis methods and computational tools for creating a model on the NMR-50 are presented. Important geometrical and thermal-hydraulics design parameters of NMR-50 are shown in Table 2.

Table 2

Geometry and thermal-hydraulics design parameters for the NMR-50 core.

\begin{tabular}{ll}
\hline Parameter & Value \\
\hline Geometry & 256 \\
Number of fuel assemblies & $18 \times 18$ \\
Fuel assembly arrangement & $2.73 \mathrm{~m}$ \\
Equivalent core diameter (m) & $1.706 \mathrm{~m}$ \\
Total fuel length & $1.372 \mathrm{~m}$ \\
Active fuel length (m) & 57 \\
Number of control blades & \\
Thermal-Hydraulics & $165 \mathrm{MWt}$ \\
Reactor thermal power & $2.23 \times 10^{6} \mathrm{~kg} / \mathrm{h}$ \\
Core coolant flow rate & $3.19 \times 10^{5} \mathrm{~kg} / \mathrm{h}$ \\
Steam flow rate & $7.19 \mathrm{MPa}$ \\
Nominal pressure in steam dome & $278.5^{\circ} \mathrm{C}$ \\
Core inlet temperature & $287.5{ }^{\circ} \mathrm{C}$ \\
Coolant saturation temperature & $20.75 \mathrm{~kW} / \mathrm{L}$ \\
Average power density & $7 \mathrm{~kW} / \mathrm{m}$ \\
Average linear power density & $3.7 \mathrm{~m}^{2}$ \\
Total core flow area & $1.12 \mathrm{~m}^{2}$ \\
Core bypass flow area & 0.143 \\
Average core exit quality &
\end{tabular}

CASMO-4 (Ekberg et al., 1995), a well-established, industry-standard lattice physics code was used to perform pin cell and assembly calculations during the assembly design optimization and to prepare the burnup dependent cross section libraries for the core calculations. The assembly design step mainly involved varying pin size, fuel enrichment, water-to-fuel volume ratio, and void fraction. The optimum assembly enrichment split was determined using simulated annealing optimization approach. In addition, the optimum amount of burnable poison (BP) and number of BP pins were determined.

The computer code named Generation of Purdue Macroscopic Cross-Sections (GenPMAXS) is an interface between lattice physics codes and the whole core simulator PARCS (Downar et al., 2020). It provides the so-called Purdue Macroscopic cross section (PMAXS) file (Xu and Downar, 2012), which includes macroscopic and microscopic cross-sections, discontinuity factors, kinetic data, and yields for the poisons. The cross sections are linearized as a function of state variables except for the moderator density and void fraction that use a quadratic variation. In a PARCS depletion calculation, a multi-dimensional piecewise linear interpolation is performed to obtain the partial derivatives. The verification and validation of the cross section 
interpolation scheme on fuel temperature (Doppler) and moderator temperature have been performed (Xu and Downar, 2012). However, the accuracy of the cross section linear interpolation scheme on coolant void fraction was not considered, and hence additional assessment is performed as discussed below.

A core simulator PARCS was used to perform whole core depletion calculations in order to determine the cycle length and to ensure no thermal design violation due to power peaking. In order to maximize the cycle length (i.e., cycle burnup) for a fixed specific power and fuel enrichment, a single-batch fuel management scheme was selected. In PARCS, the fuel assembly was modeled to account for the top and bottom axial reflectors and the active core region as well as the radial reflectors. The model was constructed using 1 node per fuel assembly in the radial direction and 11 nodes per assembly in the axial direction, which was mapped to the respective thermal-hydraulics nodes. A full core radial schematic view of the NMR-50 is shown in Fig. 1, which consists of 256 fuel assemblies, 57 control rod blades, and reflectors.

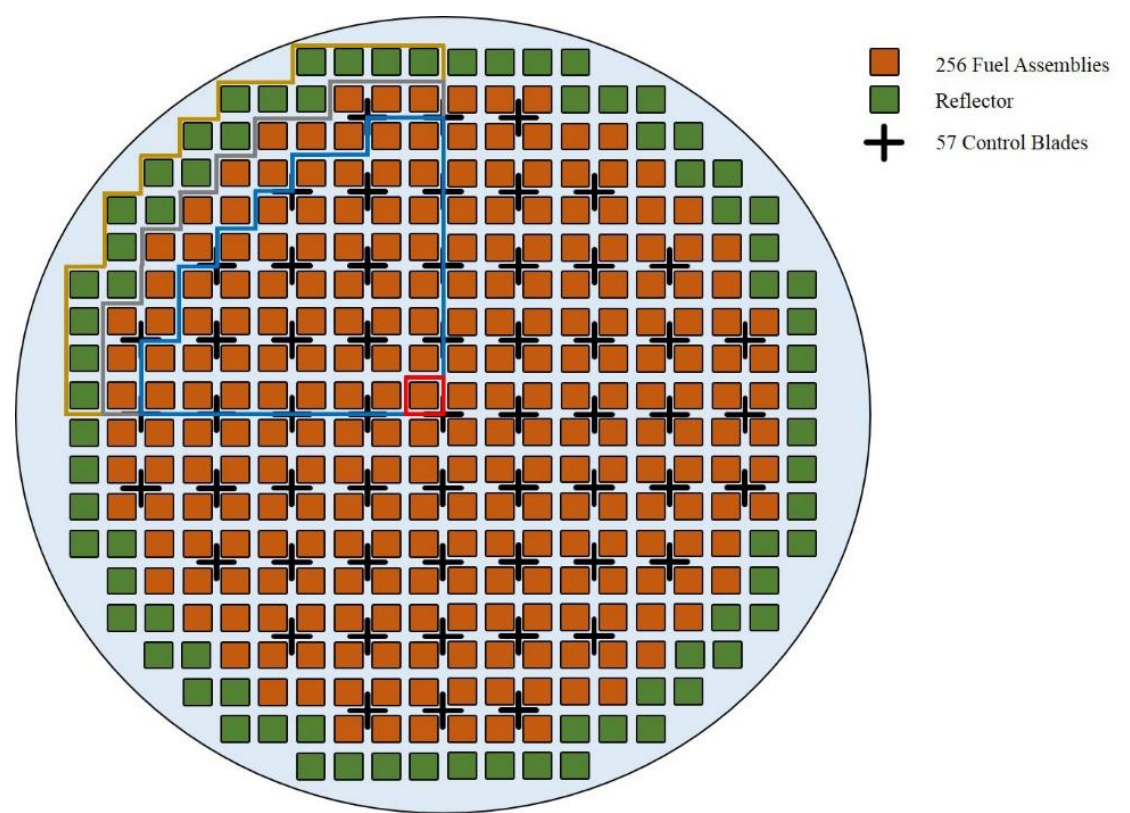

Fig. 1. A schematic view of NMR-50 core layout.

A best estimate thermal hydraulics code RELAP5 (U.S. NRC, 2006) was coupled, via parallel virtual machine, with PARCS to consider local thermal feedback effects that are vital in BWR's. The Hench-Gillis correlation (Hench and Gillis, 1981) for critical quality boiling length was used to determine the MCPR. To account for the thermal feedbacks through RELAP5 calculations, the fuel assemblies in the PARCS model were divided into three groups of similar power, and each group was represented by a single thermal-hydraulics $(\mathrm{T} / \mathrm{H})$ channel. These three $\mathrm{T} / \mathrm{H}$ channels represent the hot, average, and peripheral channels. An additional bypass channel was defined to account for the coolant flowing through the inter-assembly gaps as well as reflector regions. The four $\mathrm{T} / \mathrm{H}$ channels are marked by colored lines in the top-left quarter core in Fig. 1. In a quarter core, the hot channel includes the center assembly, the average 
channels include 46 assemblies, and the peripheral channels include 17 assemblies. The inlet loss coefficients (K_loss) of the four T/H channels were determined to yield approximately equal power to flow ratios (Ishii et al., 2013). A RELAP5 full primary system nodalization model of the NMR-50 is shown in Fig. 2, in a simplified schematic.

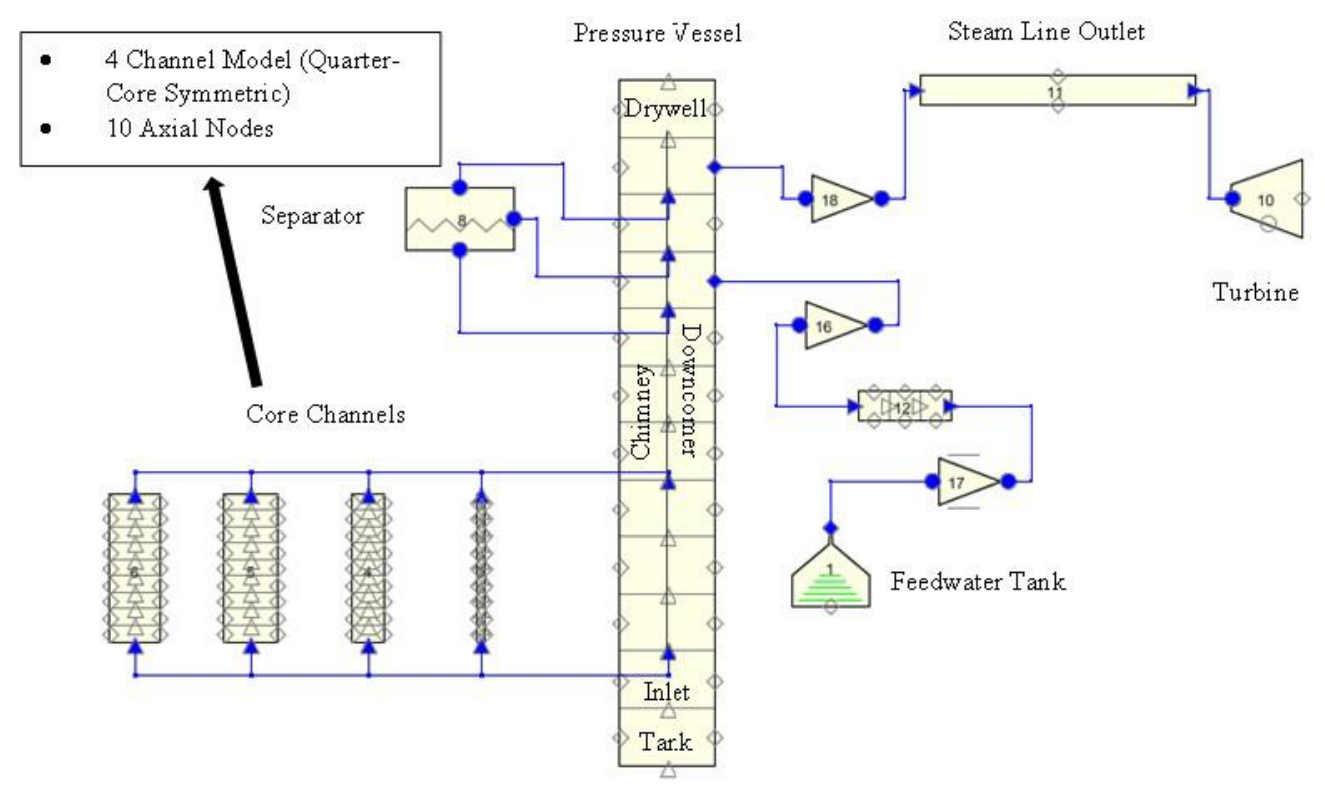

Fig. 2. RELAP5 nodalization diagram (simplified schematic) for the NMR-50 primary system using symbolic nuclear analysis package.

The parallel virtual machine (pvm) was used to couple PARCS and RELAP5 via a general interface (GI). The use of pvm manages the transfer of neutronics and thermal hydraulics information and map temporal evolution between the selected codes (Agung et al., 2013). PARCS calculates the initial power distribution using the fuel temperature and coolant void fraction distributions at the previous time point. The power distribution is passed to RELAP5 via GI, and then RELAP5 performs the T/H calculation and passes new distributions of fuel temperature and coolant void fraction to PARCS via GI. The alternating calculations of PARCS and RELAP5 are repeated until a set of user-specified convergence criteria is met. Kozlowski et al. (2004) provided a more detailed description and an assessment of this coupling methodology.

PARCS and RELAP5 codes are both chosen by the U.S Nuclear Regulatory Commission (NRC) as its best estimate core neutronics and best estimate thermal-hydraulics system code, respectively (Downar et al., 2002). This implies that sufficient verification and validation have been performed. In addition, the qualification of CASMO-4/PARCS/RELAP-5 was assessed during the neutronics design of the Purdue University 200 MWe SBWR (Tinkler and Downar, 2003). Furthermore, extensive coupled codes (PARCS/RELAP) technique development and validation, regarding steady-state as well as transient scenarios, have been performed to ensure proper consideration of important thermal feedbacks (Abarca et al., 2011; Agung et al., 2013; Grgić et al., 2013; Kozlowski et al., 2004). 
The efficiency of the functionalization scheme in PMAXS and the accuracy of the cross section linear interpolation scheme were assessed. Considering a piecewise linear interpolation scheme, a sufficient number of cross section data points are required to reduce the error in the computation of partial derivatives. Error in calculating partial derivatives would affect the whole core eigenvalue and depletion calculation, which could result in a cycle length that is off by weeks or even months. Thus, a sensitivity study of the branching calculation on the computation of eigenvalue was performed.

Since voiding is the predominant factor in moderator density changes in BWR's, void branching calculation was examined in detail. A reference case with a nominal thermalhydraulics operating conditions were first established, followed by a perturbed case with a reduction in void fraction. These conditions include a fuel temperature of $900 \mathrm{~K}$, a moderator temperature of $560 \mathrm{~K}$, and a void fraction of $40 \%$ and $5 \%$ corresponding to the reference and perturbed case, respectively. The procedure to assess the accuracy of the cross section interpolation scheme was done by analyzing the difference in the k-infinity eigenvalue from PARCS single assembly depletion with reflective boundary condition and PMAXS file obtained by performing branching calculation versus the reference CASMO-4 depletion results.

Fig. 3 compares the k-infinity values obtained from the PARCS calculations with different cross section sets with the CASMO-4 reference solution. When the conventional branching calculation procedure derived from the SIMULATE-3 case matrix (S3C), the k-infinity of the reduced void case shows a maximum difference around $100 \mathrm{pcm}$. To reduce this large error, the branching calculation procedure was refined until the eigenvalue difference was within $10 \mathrm{pcm}$. The depletion branching calculation was also refined in the first $15 \mathrm{GWd} / \mathrm{tU}$ where gadolinium content is burned out. This refinement reduced the deviation in eigenvalue to below $35 \mathrm{pcm}$. Table 3 compares the depletion and void branches between the refined and the conventional S3C model.

Table 3

Comparison of Depletion and void branches between refined and conventional methods.

\begin{tabular}{lll}
\hline & Refined & Conventional (S3C Case Matrix) \\
\hline \multirow{2}{*}{ Depletion Branch } & $0,0.1,0.5,1,1.5, \ldots, 20,25,30$, & $0,0.5,2.5,4,5,6,7.5,9,10,11$, \\
& $\ldots, 60$ & $12.5,15,17.5, \ldots, 60$ \\
\hline Void Branch & $0,10,20,30, \ldots, 80,100$ & $0,40,80,100$ \\
\hline
\end{tabular}




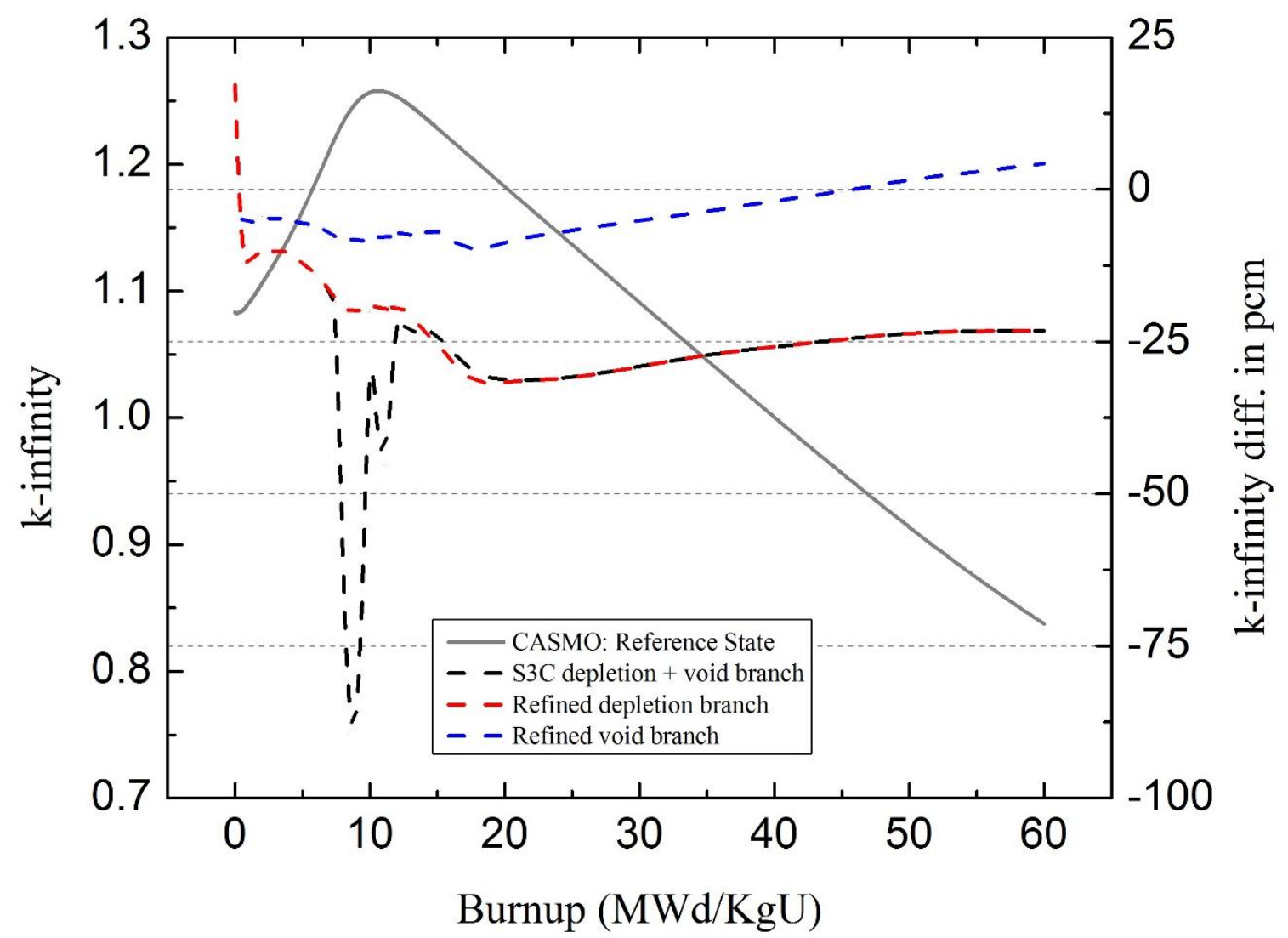

Fig. 3. Comparison of k-infinity eigenvalues of refined and conventional branching calculations with exact depletion solution: $\mathrm{T}_{\text {fuel }}=900 \mathrm{~K}, \mathrm{~T}_{\text {mod }}=560 \mathrm{~K}$, and $\alpha=0.05$.

Note that cross section library generation is the most time-consuming procedure in the overall neutronics simulation. This is taken into consideration when the simulated annealing algorithm is devised. 


\section{Optimization approach}

The focus on optimization is to achieve the targeted 10-year cycle length with a minimum fissile loading. This optimization process was taken by a systematic step-wise approach to reduce the design domain. Moreover, simulated annealing based optimization method was used in deriving an optimized assembly design.

The maximum specific power was first determined in order to achieve a 10-year cycle length with a maximum fuel enrichment of $5 \mathrm{wt} \%$. This corresponds to roughly $11 \mathrm{~W} / \mathrm{gU}$. Considering the reduction in the assembly average enrichment due to the fuel enrichment split within an assembly in order to reduce the local power peaking, the specific power was further reduced to around $9 \mathrm{~W} / \mathrm{gU}$. Then, using CASMO-4, pin cell calculations were performed to determine the optimum pin size, moderator-to-fuel ratio, and average enrichment. VC was calculated by performing a branching calculation at different void fraction. Next, assembly calculations were performed to determine the optimum enrichment split. This was accomplished using an SA optimization algorithm. Moreover, the number of burnable poison pins and its concentration were optimized to hold down the excess reactivity with a sufficient cold SDM. The axial zoning design of the burnable poison fuel rods was optimized such that axial power peaking factor is minimized. The fuel pin cell and part of the fuel assembly study was discussed in a previous publication (Odeh and Yang, 2015), but to provide a coherent flow of the paper, some of the study is summarized with minor modification.

\subsection{Fuel pin cell}

Fuel pin-cell models were developed to represent the average assembly behavior. Pin cell depletion calculations were performed and the critical burnup that represents the cycle burnup of single-batch scheme was determined. The critical burnup was estimated at a state of $\mathrm{k}_{\infty}=1+$ leakage fraction. The leakage fraction was conservatively assumed to be $7 \%$.

The critical cycle burnup was analyzed as a function of the pin outside diameter and the water-to-fuel volume ratio at a fixed enrichment. The critical cycle burnup corresponding to a 10 -year cycle length was determined. Then the pin diameter and water-to-fuel volume ratio to yield a 10-year cycle length was determined for different fuel enrichments. The contour lines of 10-year cycle length for five different enrichments are shown in Fig. 4 as dotted lines. The color plot in Fig. 4 is the contour plot of VC. Fig. 4 also shows the critical heat flux (CHF) limits (solid horizontal line) for two different assembly lattices, which was determined by the smallest pin diameter for a given assembly lattice and a conservative three-dimensional power peaking factor $\left(\mathrm{F}_{\mathrm{Q}}\right)$ of 3.5. The dashed lines show the pin diameter versus water-to-fuel volume ratio for four different assembly lattices. 


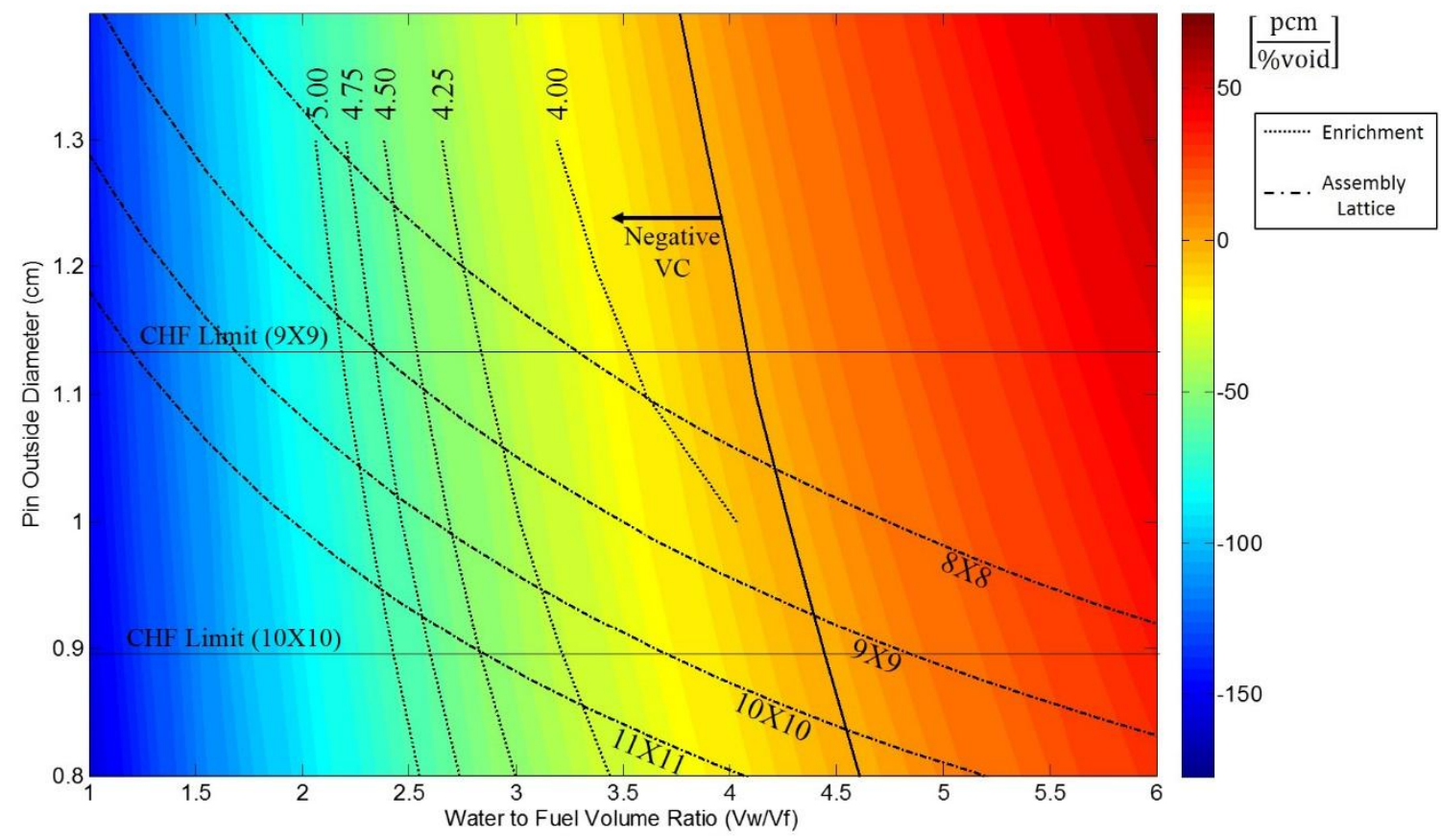

Fig. 4. Contour plots of fuel enrichment required for10-year cycle length, critical heat flux limit and assembly lattice as well as color plot for void coefficient (pcm/\%void).

From Fig. 4, it can be seen that with increased water-to-fuel volume ratio, the average enrichment required for a 10-year cycle length decreases. However, the imposed VC constraint yields a minimum average enrichment around $4.5 \mathrm{wt} \%$. Since a smaller sized pin is desirable from a standpoint of minimizing the fissile loading, a $1.05 \mathrm{~cm}$ fuel pin diameter, water-to-fuel volume ratio of 2.7 , and an average enrichment of $4.5 \mathrm{wt} \%$ were chosen for an optimum average fuel-pin design.

\subsection{Fuel Assembly}

\subsubsection{Enrichment split}

Fuel enrichment distribution within assembly allows a better fuel utilization (fuel cost), more even burnup, and lower local power peaking. The presence of water rods and interassembly gap provides more moderation for the fuel pins adjacent to them, thus would cause significant power increase in these pins if a single enrichment were used for all the fuel pins. This can be shown in Fig. 5, which shows the relative pin power for a fuel assembly with a uniform enrichment distribution. 


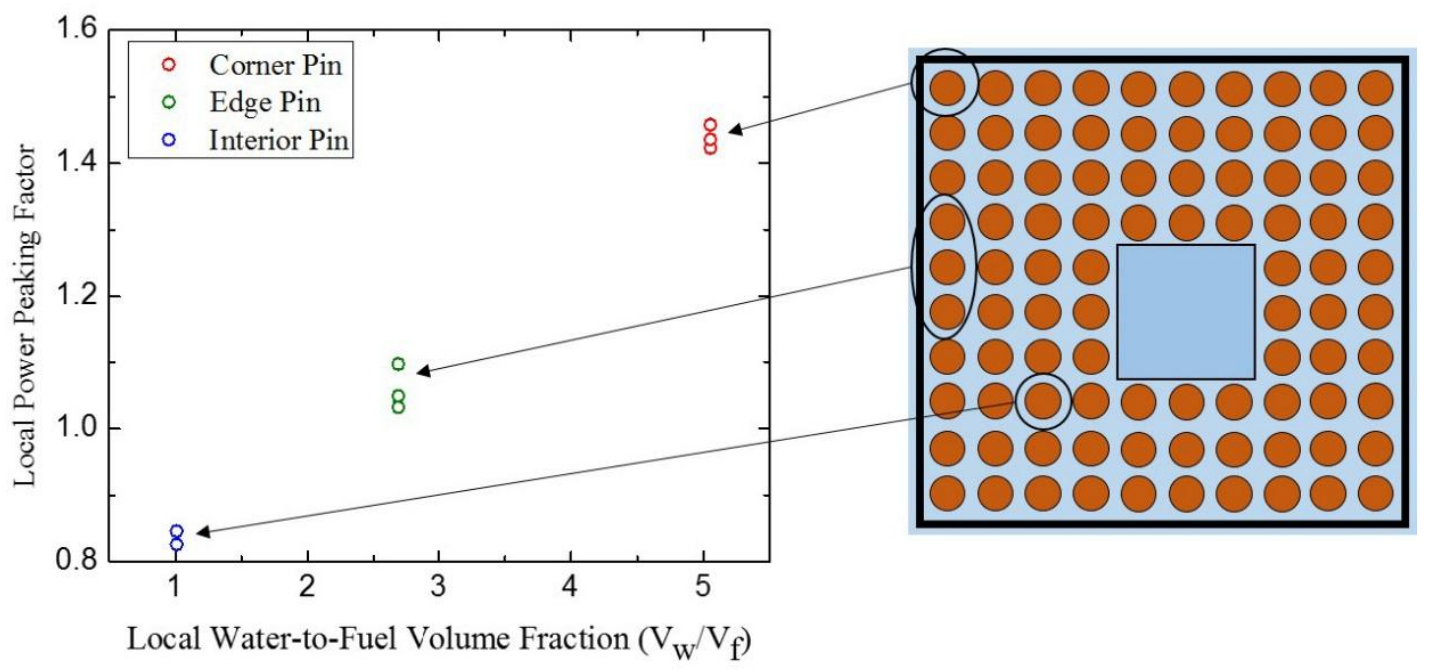

Fig. 5. Local pin power peaking factor as a function of local water-to-fuel volume ratio.

Fig. 5 shows an approximately linear relationship between the relative pin power and the local water-to-fuel volume ratio. This behavior was utilized in a way to determine an optimum fuel enrichment split by correlating individual pin enrichment and local water-to-fuel volume ratio. Therefore, fuel pins with high local water-to-fuel volume ratio were assigned a lower enrichment, while pins with low local water-to-fuel volume ratio were assigned a higher enrichment. The optimum enrichment domain for an individual pin can be determined by analyzing the relative pin peaking factor as a function of the enrichments of the designated pin and its surrounding pins, which is shown in Fig. 6 for four different fuel pin locations. This analysis summarized in Fig. 6 was used to set an enrichment domain on the different fuel types such that the local pin power peaking factor is approximately unity. 

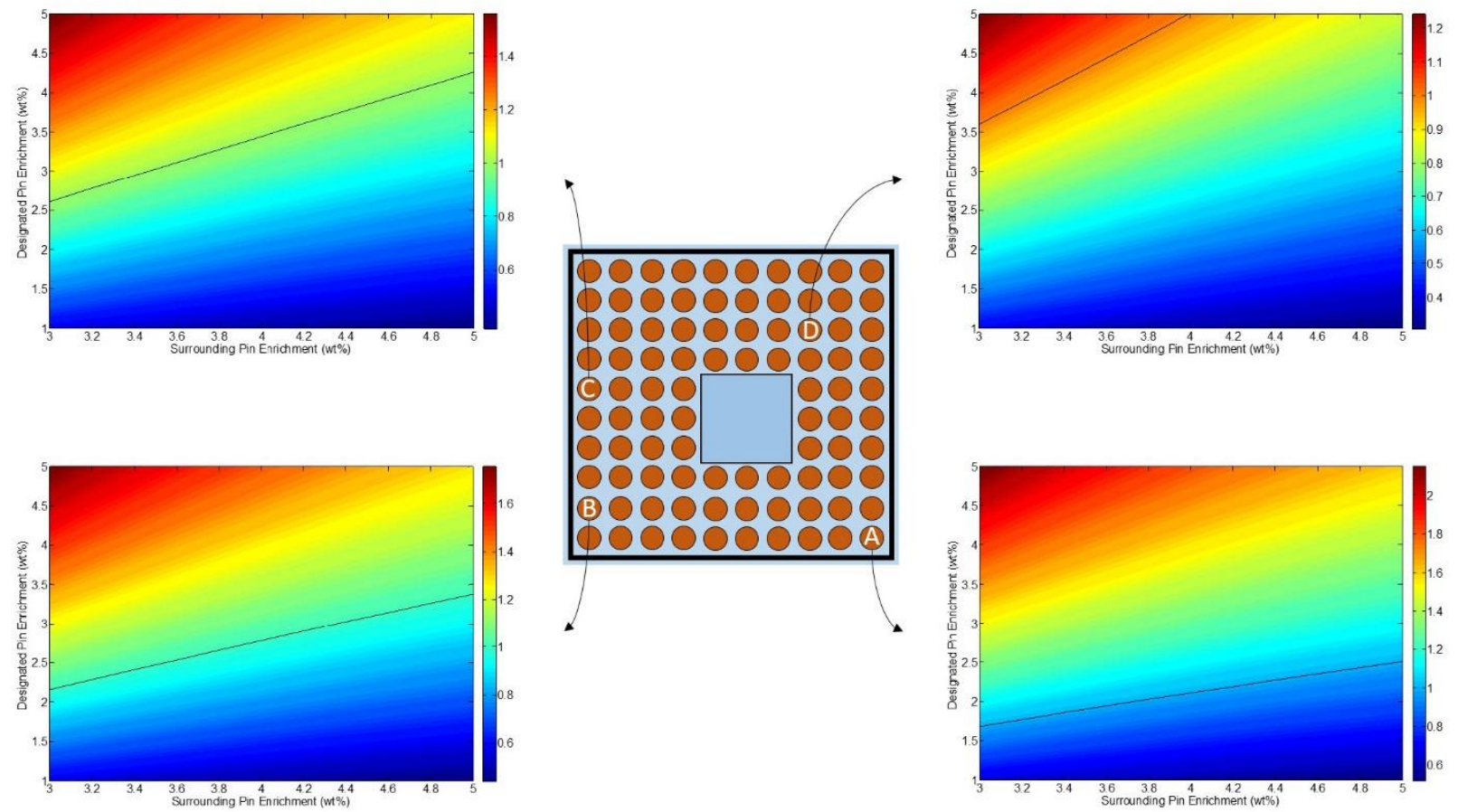

Fig. 6. Pin power peaking factors of four different fuel pin types as a function of the enrichments of the designated pin and its surrounding pins.

Typical practice in the industry involves maintaining the number of different fuel pin enrichments within an assembly to a minimum (Worrall, 2015). However, some assembly designs, such as AREVA Atrium 10B, have many more types of fuel pins within an assembly. This increases the degrees of freedom when searching for an optimum enrichment split. The NMR-50 assembly design employs seven different types of fuel (enrichment) pins within its assembly along with a centered water rod that occupies nine fuel pins.

\subsubsection{Burnable poison}

The type, number, and amount of burnable poison (BP) rods required within an assembly were determined. The main purpose of introducing BP is to provide excess reactivity control and power peaking control. There are numerous BP types studied, tested, and used (Renier and Grossbeck, 2001), but three primary BPs have been industrially used: boron, erbium, and gadolinium (Gd). Boron-10 has a high absorption cross section, no resonance self-shielding effects, and no other absorbing boron isotopes. Therefore, boron tends to burn out rapidly, which does not make it suitable for long life core. Gadolinium and erbium are similar in terms of their isotopic depletion chain in which both include isotopes with a reasonable absorption cross section. In addition, both gadolinium and erbium have self-shielding effects, which allow for slow burn out. This means that both are suitable for long life core. Furthermore, it was found that $\mathrm{Gd}$ is more beneficial on the basis of residual absorber penalty (Renier and Grossbeck, 2001). Since NMR-50 cannot use boric acid, a larger burden is placed on control rod blades and BP for 
excess reactivity hold-down. Therefore, gadolinium that has a relatively higher absorption than erbium was chosen. Gadolinium is used in the form of $\mathrm{Gd}_{2} \mathrm{O}_{3}$ with a specified concentration that is mixed with fuel.

The optimum gadolinium amount and number of pins were determined to hold down the excess reactivity so that the required cold shutdown margin can be obtained with the current control blade design. Gadolinium is also used to suppress local power peaking, but it requires a large amount of $\mathrm{Gd}$ than the amount required for reactivity hold down. Since the primary purpose of $\mathrm{Gd}$ is to control excess reactivity, fewer number of Gd fuel pins with higher Gd concentration are favorable. That is because the higher concentration reduces the decreasing rate of negative reactivity, due to increased thermal neutron self-shielding (Turinsky, 2010). This is shown in Fig. 7, where the gadolinium amount is conserved in all three cases. It can be noted that the assembly with a lower number of Gd fuel pins with higher concentration yields a lower residual neutron absorption content. This indicates that the residual penalty is reduced, which yields a longer cycle length. In particular, the difference in cycle length between seven and fifteen Gd fuel pin designs is approximately 2 weeks. Seven Gd fuel pin design was chosen. With the current control rod blade design, the control blade worth was determined to be around $26 \$$, though it will slightly vary depending on the final assembly design. As a result, it was found that $6.2 \mathrm{wt} \%$ enriched $\mathrm{Gd}_{2} \mathrm{O}_{3}$ is required to hold down the required excess reactivity while maintaining sufficient cold shutdown margin.

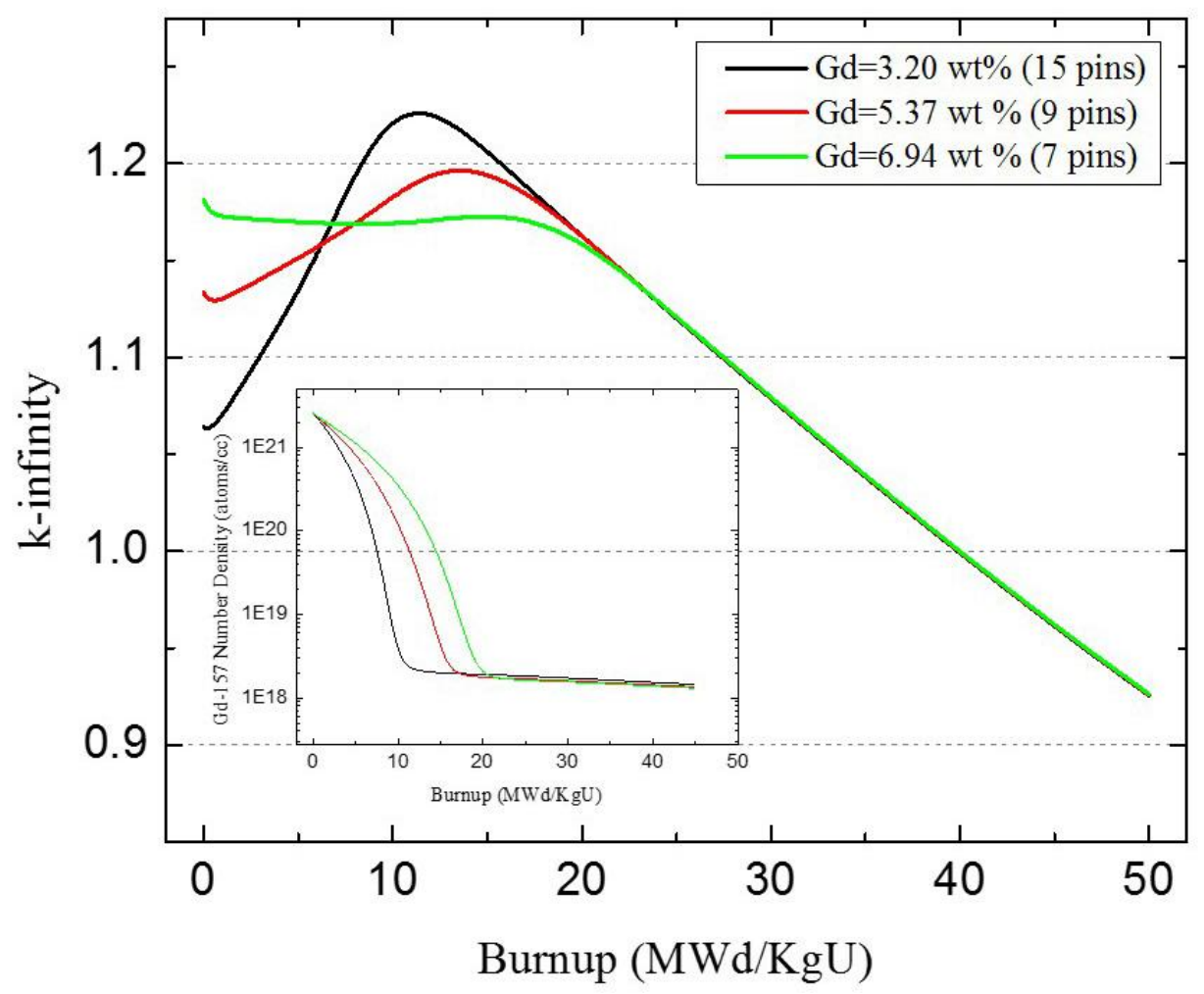

Fig. 7. Excess reactivity and Gd-157 number density behaviors for three different Gd fuel pin designs. 


\subsubsection{Simulated annealing based optimization algorithm}

Simulated annealing based optimization method was used in deriving an optimized fuel assembly design. Given a fuel pin size and a pitch determined from the pin cell study and given the fuel pin enrichment domain and the burnable poison used from the above study, the optimum fuel enrichment split within an assembly is determined by using a simulated annealing optimization algorithm. The above systematic step-wise approach reduces the design domain significantly, which enhances the overall efficiency in the search for an optimum FA. The simulated annealing main engine was based on the Metropolis algorithm (Metropolis et al., 1953).

The overall SA FA optimization algorithm requires a FA proposal logic, an objectivefunction, an acceptance probability, an initial temperature, a temperature reduction scheme, and a termination criterion. Each feature will be discussed in the following paragraphs.

To propose a new FA from the current FA, two random numbers are used. The first random number, which is an integer from one to seven, represents the fuel pin type. It is noted that NMR-50 fuel assembly is comprised of 7 fuel pin types; each of which have predetermined fixed locations, based on local moderation variation, within the assembly. These different fuel pin types mainly reside on the periphery of the assembly in order to control the local power peaking due to significant local moderation without excessive use of gadolinia. The second random number is used to determine the fuel pin enrichment to be allocated to the fuel pin type determined by the first random number. Depending on the second random number generated, the enrichment can be increased or decreased within its neighborhood. The series of proposed FA constitutes a Markov chain because each successive solution depends only on the preceding solution and random numbers. The SA algorithm is divided into stages and samples. Each stage is composed of a number of FA samples, where the samples refer to the number of neighboring FAs possible from the current FA.

The evaluation of the original objective function, i.e., cycle length requires the PARCS depletion calculation with CASMO-4 cross section library generation for each newly accepted FA design, and thus it is extremely time consuming. In order to improve the overall efficiency of the FA design optimization, the objective function was simplified to k-infinity at BOC. Once this simplified objective function is maximized, the top $10 \%$ of the proposed FAs were selected. The selected FAs were then evaluated using CASMO-4 depletion calculation where the cycle length could be estimated. Then, the optimum mutually undominated FAs were determined and the best candidate was evaluated using the full-core PARCS/RELAP5 coupled calculation.

The acceptance probability of the proposed FA was determined according to the Metropolis algorithm, which is computed using an exponential function similar to that of the Arrhenius equation 


$$
\mathrm{P}_{\text {acceptance }}=\left\{\begin{array}{l}
\exp \left(-\frac{\mathrm{O}\left(\mathrm{X}_{\mathrm{m}}\right)-\mathrm{O}\left(\mathrm{X}_{\mathrm{n}}\right)}{\mathrm{T}_{\mathrm{s}}}\right) ; \text { if } \mathrm{O}\left(\mathrm{X}_{\mathrm{m}}\right)<\mathrm{O}\left(\mathrm{X}_{\mathrm{n}}\right) \\
1 ; \text { otherwise }
\end{array}\right\}
$$

where $X_{m}$ and $X_{n}$ represent the new and current FA, respectively. $O(X)$ is the objective function and $T_{s}$ is the temperature variable at stage $s$. The initiation of the initial temperature is important in order to allow for efficient FA search. The temperature must be high enough in order to accept all neighboring FA proposed from the current FA, while not too high to avoid a completely random search. The initial temperature is determined by running an initialization, which consists of a number of randomly proposed FAs, and determining the average objective function and the standard deviation. As the temperature decreases, the acceptance probability decreases. The temperature reduction scheme adopted in this study uses a polynomial time annealing schedule (Aarts and Korst, 1989). The termination criteria used is based on the number of accepted FAs per stage. At any given temperature and stage, if the number of accepted FAs is less than a user defined value, then a signal for termination is sent. Other termination criteria can be used.

The search for an optimum enrichment split was performed using the SA optimization method. At first, the simulation consists of a CAMSO-4 BOC calculation with 1200 samples (FAs) per stage. The simulation was terminated at stage 150, where 180,000 FAs were generated. Of these proposed FAs, around 60,000 of them were accepted.

From this data, the top $10 \%$ FAs, based on maximizing k-infinity, were chosen for the CASMO-4 depletion calculation. Fig. 8 shows the local power peaking factor as a function of cycle length. Since a maximum cycle length with a minimum local power peaking factor is desired, there are only 12 mutually undominated FA designs. To determine an optimum candidate, the present value of the fuel assembly cost was considered. The fuel cost was determined by adding the known costs incurred in the front-end cycle. The cost of each of seven fuel pin types was considered explicitly. Then, the assembly cost divided by the cycle length is established as a unit cost. By minimizing the assembly unit cost, a few optimum FA candidates were chosen. The smallest unit cost with a relatively low local power peaking factor corresponded to the FA design with peaking factor of 1.232 and a cycle length of approximately 10.28 years, which was chosen as the optimum design for full core coupled calculation. 


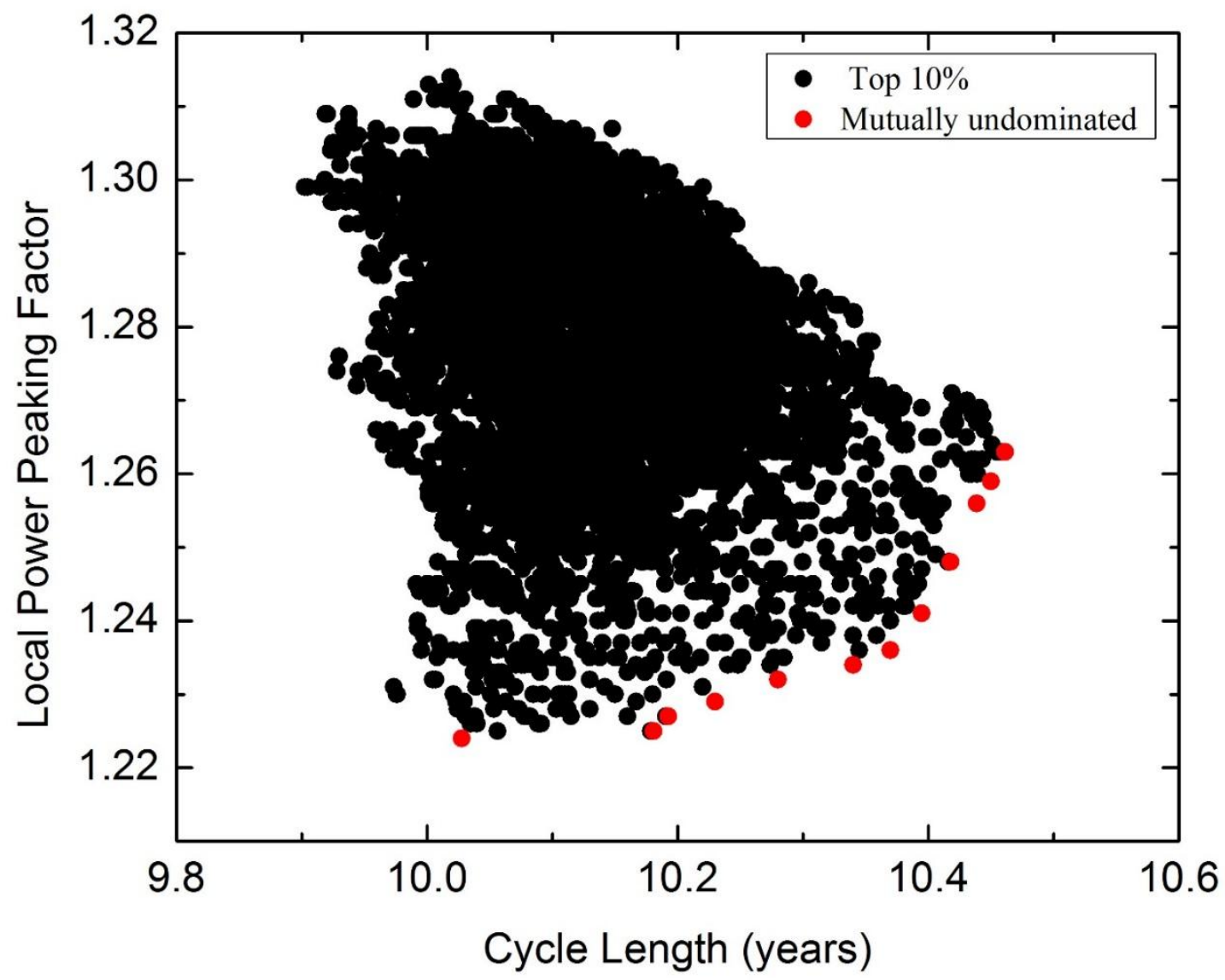

Fig. 8. Local power peaking factor versus fuel cycle length for the top $10 \%$ fuel assembly candidates.

The optimum assembly design deduced from the above step-wise optimization process is illustrated in Fig. 9. The optimized design parameters for NMR-50 FA are summarized in Table 4. The average assembly enrichment was $4.61 \mathrm{wt} \%$ and the local power peaking factor was 1.232. When compared to previous NMR-50 design (Wu et al., 2015), the fissile mass loading was reduced by $6 \%$ while maintaining the targeted 10 -year cycle length, the local power peaking factor was reduced from 1.269 to 1.232 , and the fuel cost was reduced by around $3.5 \%$. 


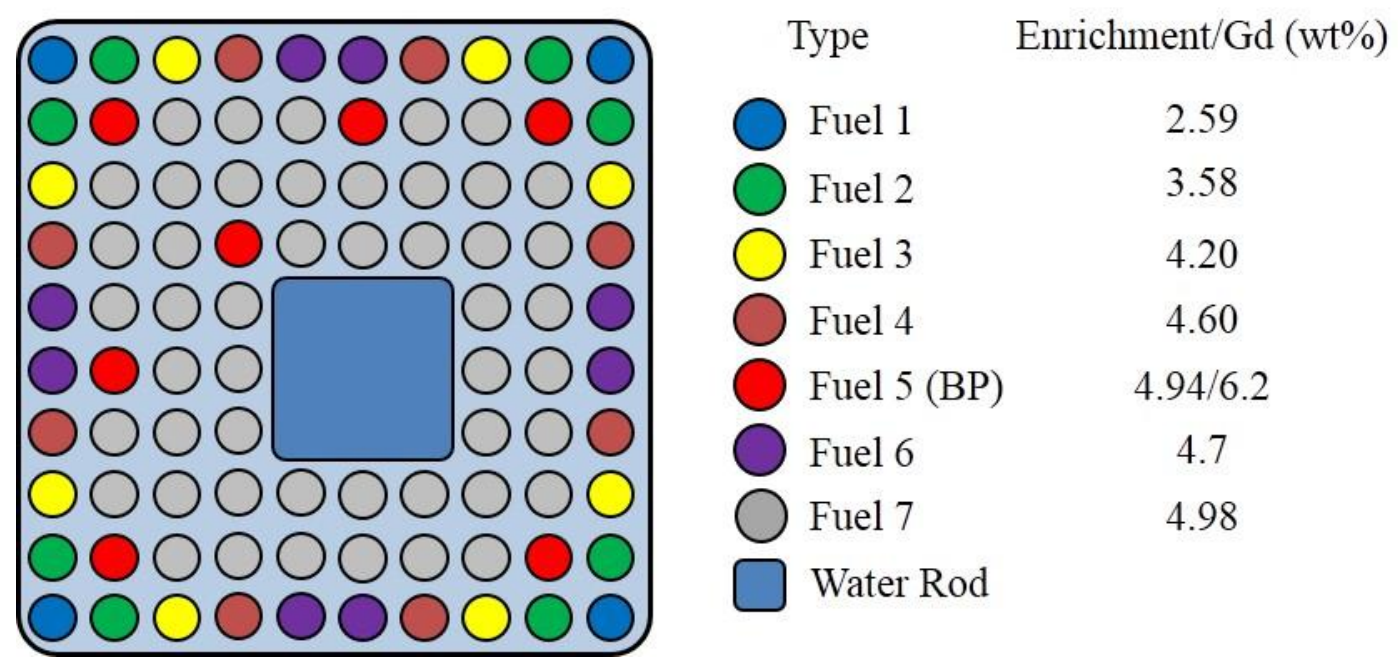

Fig. 9. Optimum fuel assembly design layout and enrichment split.

Table 4

Design parameters of the optimized NMR-50 fuel assembly.

\begin{tabular}{ll}
\hline Parameters & Values \\
\hline Fuel pin parameters & $10.5 \mathrm{~mm}$ \\
Fuel rod outside diameter & $0.6058 \mathrm{~mm}$ \\
Fuel rod cladding thickness & $0.0851 \mathrm{~mm}$ \\
Gap & 2.38 \\
Fuel characteristics & $10.45 \mathrm{~g} / \mathrm{cm}^{3}$ \\
Moderator-to-fuel volume ratio & $4.61 \mathrm{wt} \%$ \\
Fuel density at $20^{\circ} \mathrm{C}$ & $6.17 \mathrm{wt} \%$ \\
Average U-235 enrichment & \\
Average gadolinium enrichment & Zircaloy-2 \\
Fuel material & $\mathrm{UO} 2$ \\
Cladding material & Gd2O3 \\
Fuel pellet materials & \\
Burnable poison & $10 \mathrm{x} 10$ \\
Fuel assembly & $13.1 \mathrm{~mm}$ \\
Fuel rod array layout & 91 \\
Pitch of square rod array & 7 \\
Number of fuel rods per assembly & 9 \\
Number of fuel pin with burnable poison & Fuel enrichment (wt $\%)$ \\
Number of water rods per assembly & 2.59 \\
Fuel type & 3.58 \\
1 & 4.2 \\
2 & 4.6 \\
3 & 4.94 \\
4 & 4.7 \\
5 & 4.98 \\
6 & \\
7 &
\end{tabular}

\subsection{Axial zoning of BP rods}


Axial zoning of fuel assemblies, typically with different burnable poison loading, is used to counteract the reactivity penalty imposed by boiling in the upper regions of the core, which is inevitable in BWR systems. Without axial zoning, the power profile is heavily bottom skewed, which leads to uneven axial power distribution. This induces uneven fuel burnup and large spatial xenon changes. Uneven fuel burnup is uneconomical while large spatial xenon variation leads to power oscillation. An assessment of the asymmetry of power profile as well as xenon induced reactivity in NMR-50 will be discussed in the following section.

In this study, the axial zoning of Gd content was optimized such that axial power peaking factor $\left(\mathrm{F}_{\mathrm{z}}\right)$ is minimized while maintaining a hold down of excess reactivity so that the required cold shutdown margin can be achieved with the current control blade design. In the previous section, it was found that an average of $6.2 \mathrm{wt} \%$ enriched $\mathrm{Gd}_{2} \mathrm{O}_{3}$ is required to hold down the required excess reactivity.

The gadolinia fuel rod was divided into two axial zones. The total height of the active fuel was divided into 9 axial segments. The search for optimum axial zoning design involved varying the number of axial segments per zone. In addition, the $\mathrm{Gd}$ concentration in the respective axial zone was varied while maintaining an overall average concentration that is in the vicinity of the established requirement $(6.2 \mathrm{wt} \%)$. The maximum gadolinia concentration in the fuel rod is limited to $8 \mathrm{wt} \%$, which is based on industrial limit on acceptable thermal and mechanical properties (Turinsky, 2010).

PARCS full core model was developed using the optimum assembly design determined earlier. PARCS was coupled with RELAP5 for local thermal feedback. Depletion calculation was performed for the different possible axial zoning design. Discrete axial zone heights and Gd content were established for this optimization.

Throughout the depletion cycle, the maximum axial power peaking factor $\mathrm{F}_{\mathrm{z}}$ as well as the maximum $k_{\text {eff }}$ was recorded. Maximum $\mathrm{F}_{\mathrm{z}}$ versus maximum $k_{\text {eff }}$ for the different possible zoning design is shown in Fig. 10. 


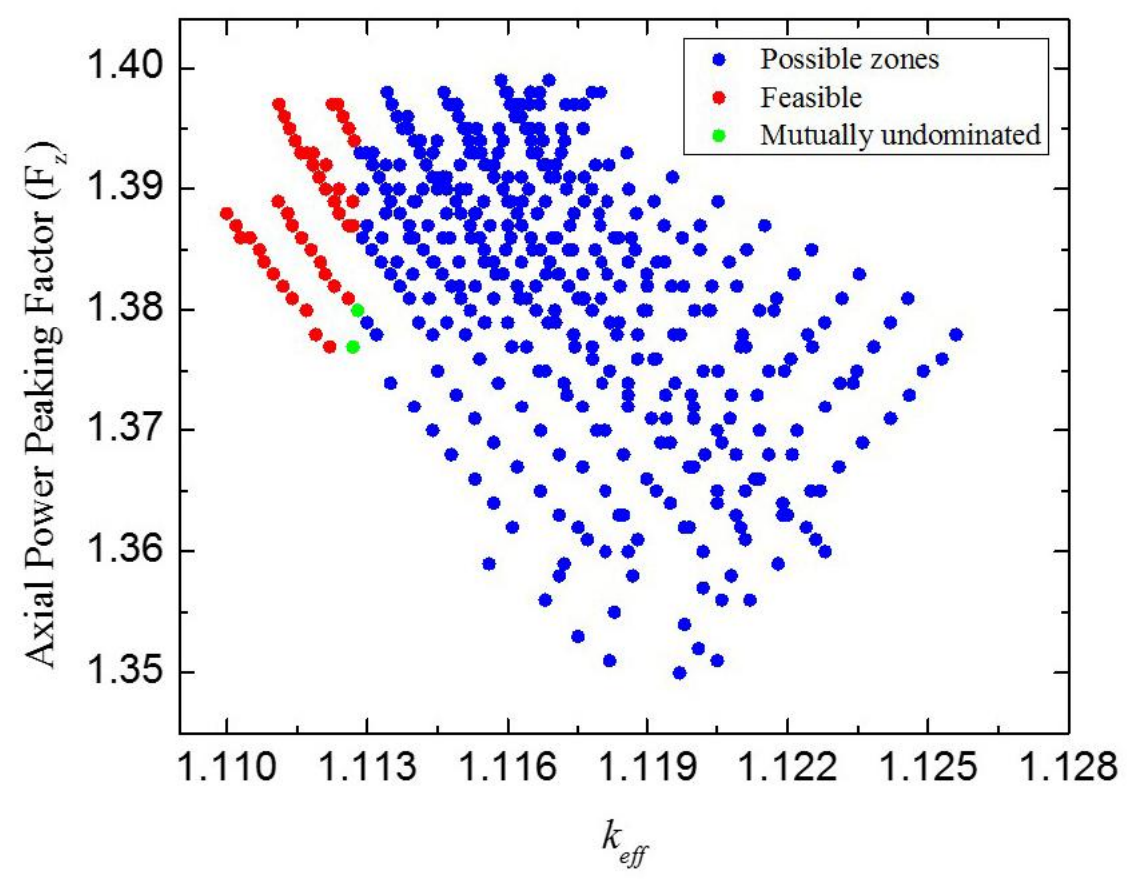

Fig. 10. Axial power peaking factor versus effective multiplication factor.

Fig. 10 shows all possible zones of the burnable poison fuel rod in which the average $\mathrm{Gd}$ concentration is around $6.2 \mathrm{wt} \%$. Given the current NMR-50 control rod blade worth, a maximum allowable $k_{\text {eff }}$ is defined in order to ensure sufficient cold shutdown margin. This results in certain feasible zoning designs. With a goal of minimizing axial power peaking factor and maximizing $k_{\text {eff, }}$, there are two mutually undominated zoning designs. The lower axial power peaking factor was chosen as the optimum axial zoning design. The geometry and material distribution of the optimized axial zoning of the NMR-50 gadolinia fuel rod is illustrated in Fig. 11. The average Gd concentration was $6.17 \mathrm{wt} \%$, with 6.7 and $5.1 \mathrm{wt} \%$ in the bottom and top zones, respectively. When compared to the previous NMR-50 design (Wu et al., 2015), the total amount of $\mathrm{Gd}$ within an assembly was reduced by $40 \%$ while maintaining the required hold down of excess reactivity. In addition, the total power peaking factor at BOC was reduced from 2.98 to 2.59 . 


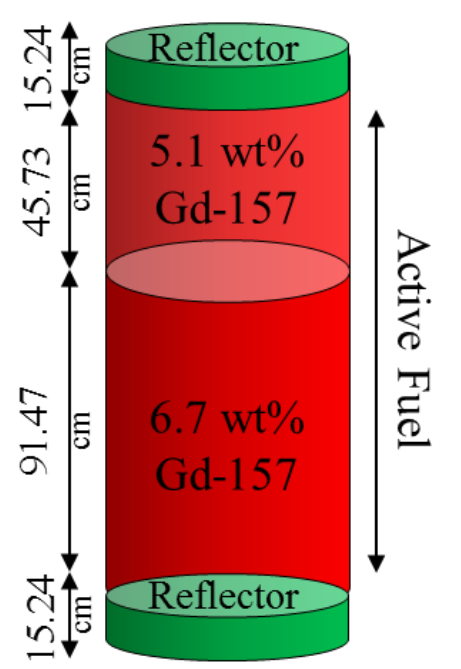

Fig. 11. Axial zoning of gadolinia fuel rod design.

\section{NMR-50 design and performance}

Using the optimum fuel assembly design showed in Fig. 9 and 11, a full core depletion calculation with PARCS and RELAP5 were performed to determine the cycle length and to evaluate the thermal safety margins. Moreover, the component-wise reactivity coefficients and cold shutdown margin were evaluated. A preliminary study on the NMR-50 vulnerability to xenon induced-power oscillations was also assessed. Finally, the potential consequences of long life core on structural material is addressed.

\subsection{Cycle length and thermal safety margins}

Performance and safety margins are determined during depletion in order to ensure safe operation throughout the 10-year cycle length. The Gd will burn out during the initial stages, which adds a positive reactivity and compensates for the negative reactivity due to fuel burnup. As a result, an overshooting in reactivity could lead to a power increase, in turn endangering the MCPR or MFLPD limits. However, proper optimization of gadolinia fuel rods provided minimum overshooting in reactivity as illustrated in Fig 7.

At each time point, the criticality was maintained by adjusting the control blade bank position. The Control Cell Core approach was used for the control rod programming. The Control Cell Core minimizes the impact of control-rod blade movement on the radial power distribution (Tong, 1988) and the buildup of burnup shadowing (Turinsky, 2010). Only two group of control rod blades in a control cell, also known as the control bank, were utilized and interchanged during the reactor operation.

The core depletion calculation yielded a cycle length of 10.2 years. Fuel cycle depletion characteristics are summarized in Table 5. The control blade insertion position is represented by the notch values for a total of 19 control blades, between 0 and 3192 per control blade that 
represent the fully withdrawn and the fully inserted states, respectively. The indicated thermal margins are in terms of the minimum and maximum value of the CPR and FLPD respectively. This corresponds to the most limiting fuel assembly within the core. Note that both MFLPD and MCPR satisfy the imposed design constraints with large margins throughout the 10-year cycle. This is due to the reduction in power density that provides an increased thermal safety margin when compared to SBWR-200.

Table 5

Fuel cycle performance parameters of the NMR-50.

\begin{tabular}{llllllllll}
\hline $\begin{array}{l}\text { Operation } \\
\text { time } \\
\text { (years) }\end{array}$ & $\begin{array}{l}\text { Average } \\
\text { burnup } \\
(\mathrm{GWd} / \mathrm{tU})\end{array}$ & $k_{\text {eff }}$ & $\begin{array}{l}\text { Control } \\
\text { blade } \\
\text { notch }\end{array}$ & $\begin{array}{l}\text { Overall } \\
\text { power } \\
\text { peak }\end{array}$ & $\begin{array}{l}\text { Radial } \\
\text { power } \\
\text { peak }\end{array}$ & $\begin{array}{l}\text { Axial } \\
\text { power } \\
\text { peak }\end{array}$ & $\begin{array}{l}\text { Axial } \\
\text { offset } \\
(\%)\end{array}$ & $\begin{array}{l}\text { MFLPD } \\
(\mathrm{kW} / \mathrm{m})\end{array}$ & MCPR \\
\hline 0.0 & 0.00 & 1.00002 & 25296 & 2.59 & 1.52 & 1.30 & -10.96 & 13.50 & 2.22 \\
1.0 & 3.05 & 1.00036 & 30241 & 2.14 & 1.32 & 1.22 & -9.81 & 11.70 & 2.19 \\
2.0 & 6.11 & 1.00014 & 30796 & 2.11 & 1.31 & 1.23 & -8.51 & 11.74 & 2.14 \\
3.0 & 9.16 & 1.00010 & 31351 & 1.92 & 1.29 & 1.23 & -7.85 & 11.78 & 2.10 \\
4.0 & 12.21 & 1.00002 & 30846 & 1.66 & 1.30 & 1.20 & -9.35 & 10.91 & 2.12 \\
5.0 & 15.27 & 1.00002 & 28767 & 1.76 & 1.21 & 1.19 & -9.33 & 10.48 & 2.07 \\
6.0 & 18.32 & 1.00020 & 25679 & 2.07 & 1.33 & 1.38 & -0.41 & 12.61 & 2.03 \\
7.0 & 21.37 & 1.00004 & 20300 & 1.79 & 1.23 & 1.16 & -1.84 & 10.57 & 2.28 \\
8.0 & 24.43 & 1.00017 & 13008 & 1.91 & 1.23 & 1.16 & -12.50 & 11.35 & 2.22 \\
9.0 & 27.48 & 1.00003 & 7472 & 2.11 & 1.37 & 1.31 & -14.80 & 12.67 & 2.14 \\
10.0 & 30.53 & 0.99998 & 1428 & 2.49 & 1.67 & 1.56 & -17.62 & 18.25 & 1.99 \\
10.2 & 31.04 & 0.99977 & 848 & 2.42 & 1.63 & 1.54 & -17.70 & 17.60 & 2.00 \\
\hline
\end{tabular}

The axial power profile is of significant importance, especially in BWRs, due to two-phase flow nature. It is necessary to limit overall power tilting for safe reactor operation (ABWR Design Control Document, 1997). The behavior of the axial power profile, the highest value corresponding to the hottest fuel assembly, as a function of the reactor operation time is shown in Fig. 12. It can be seen that the axial power profile is bottom skewed, especially during the early stage of the cycle. The degree of axial power asymmetry is represented by the axial offset (AO), which is defined as

$$
\mathrm{AO}=\left(\frac{\mathrm{P}_{\mathrm{U}}-\mathrm{P}_{\mathrm{L}}}{\mathrm{P}_{\mathrm{U}}+\mathrm{P}_{\mathrm{L}}}\right) \cdot 100,
$$

in which $\mathrm{P}_{\mathrm{U}}$ and $\mathrm{P}_{\mathrm{L}}$ are the total power at the upper half and lower half of the reactor core, respectively. The AO indicates the spatial non-uniformity presence of ${ }^{135} \mathrm{Xe}$. From Fig. 12, it can be observed that the axial offset varies during the reactor operation. Large AO causes large spatial xenon changes that may induce a large power oscillation. This could threaten the safety of reactor operation. Spatial xenon effect on NMR-50 will be discussed in the later subsection. 


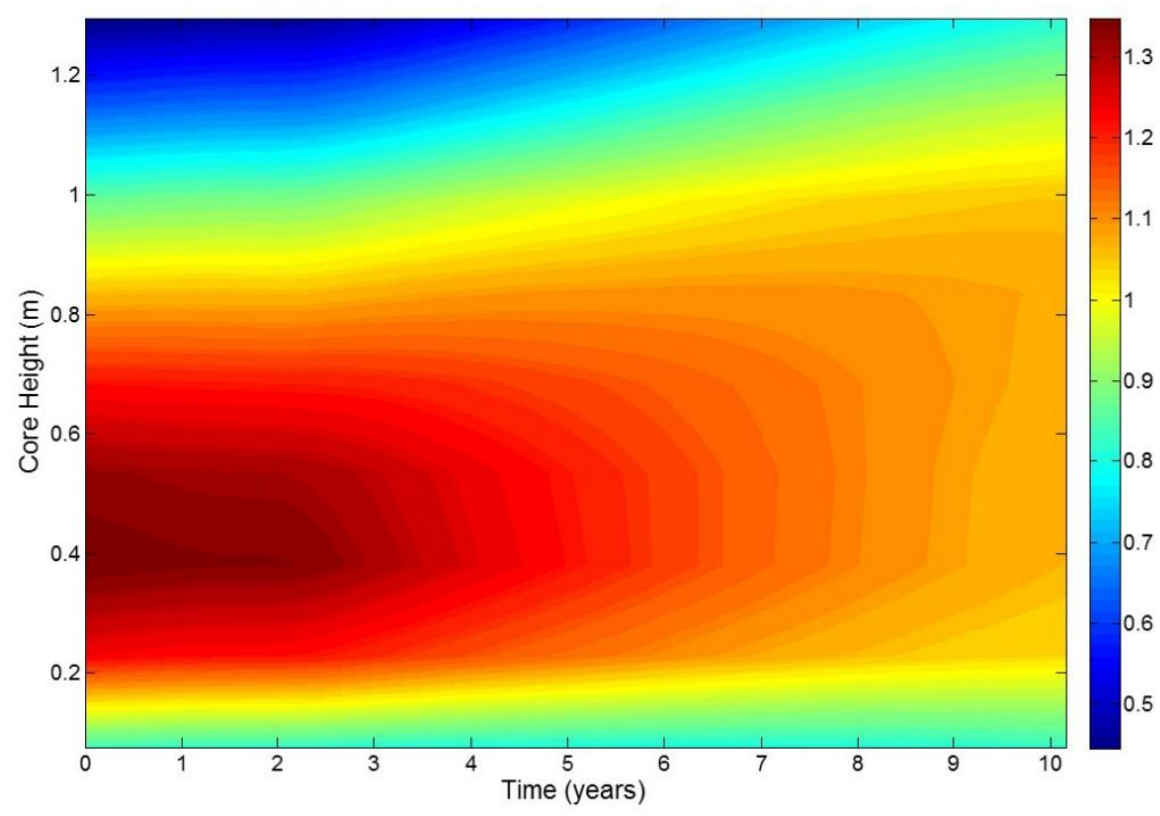

Fig. 12. Temporal axial power profile at the hottest assembly.

As a confirmation of proper coupling calculation between PARCS and RELAP5, the core coolant mass flow rate response to power changes was analyzed. The flow rate variation within the hottest and peripheral assemblies during reactor operation is shown in Fig. 13. As power increases in certain fuel assemblies, the void fraction increases and the coolant flow rate is increased such that the exit pressure equals to the pressure boundary condition. The core thermal hydraulics performance of NMR-50 design is summarized in Table 6. 


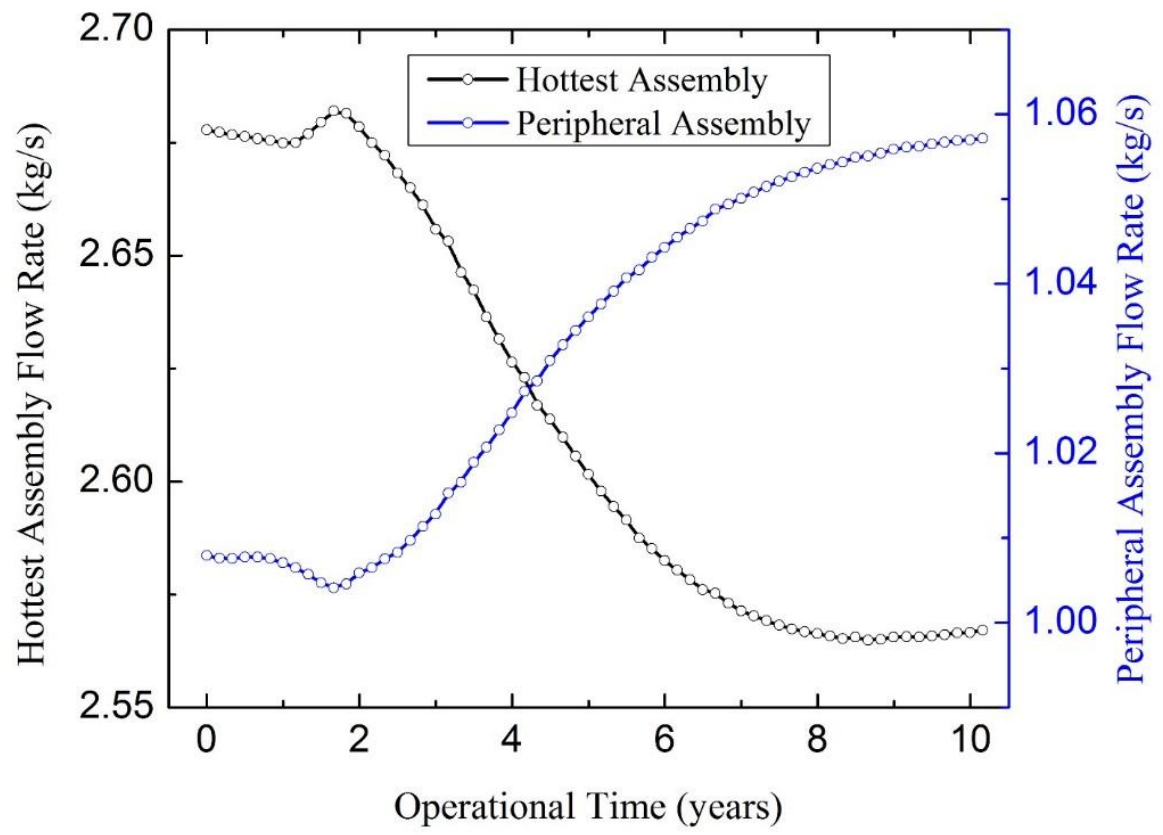

Table 6

Fig. 13. Zonal coolant flow variation during operation.

Core thermal hydraulics performance parameters of the NMR-50.

\begin{tabular}{ll}
\hline Parameter & Value \\
\hline Core pressure drop & $29.4 \mathrm{kPa}$ \\
Average core void fraction & 0.428 \\
Maximum exit void fraction & 0.750 \\
Core average exit quality & 0.144 \\
\hline
\end{tabular}

\subsection{Reactivity feedback coefficients and shutdown margin}

Doppler and void reactivity coefficients are the main feedback mechanism in BWRs. The Doppler reactivity coefficient is the most significant quenching mechanism in short term transients due to its instantaneous reactivity feedback. Such a scenario is evident in the rapid power excursion by means of control blade ejection (ABWR Design Control Document, 1997). During NMR-50 operation, the production of, mainly, ${ }^{240} \mathrm{Pu}$ contributes to a more negative Doppler reactivity coefficient with burnup as illustrated in Fig. 14. 


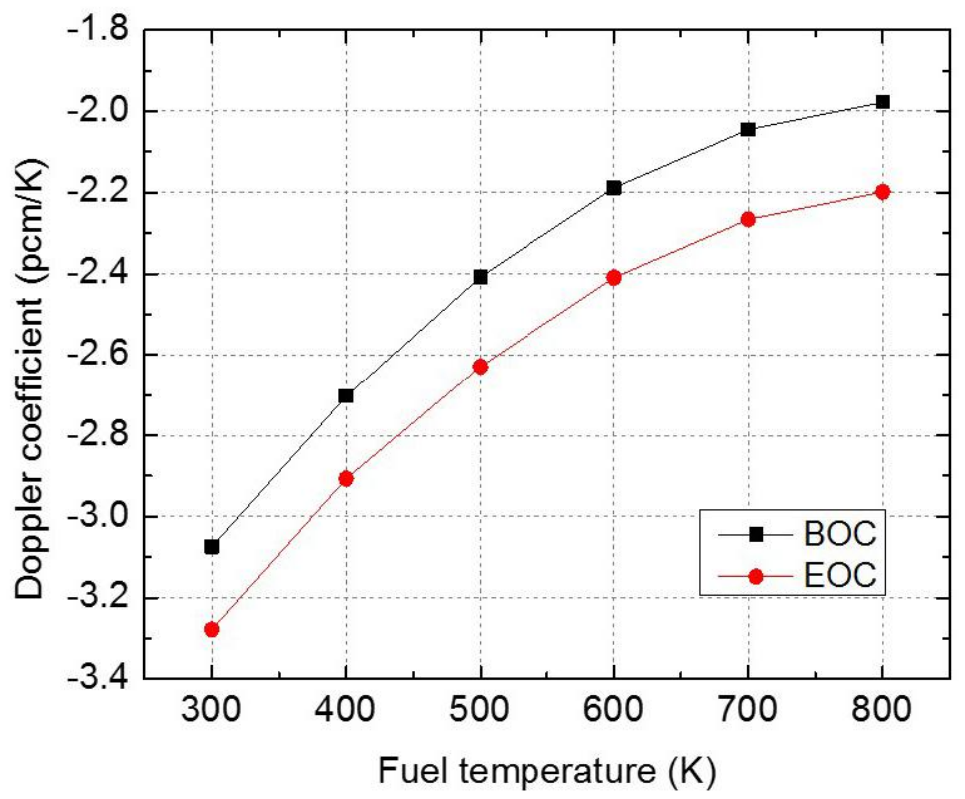

Fig. 14. Fuel temperature coefficient as a function of fuel temperature at BOC and EOC.

Void reactivity feedback is most important in stabilizing and controlling the reactivity during reactor operation. Moreover, it is used to control the reactor power output by adjusting the core-coolant flow rate. During NMR-50 operation, the production of plutonium as well as fission products results in a more negative void reactivity coefficient (Oka, 2010) with burnup as illustrated in Fig. 15. Both Doppler reactivity coefficient and void coefficient are used to compute the cold shutdown margin.

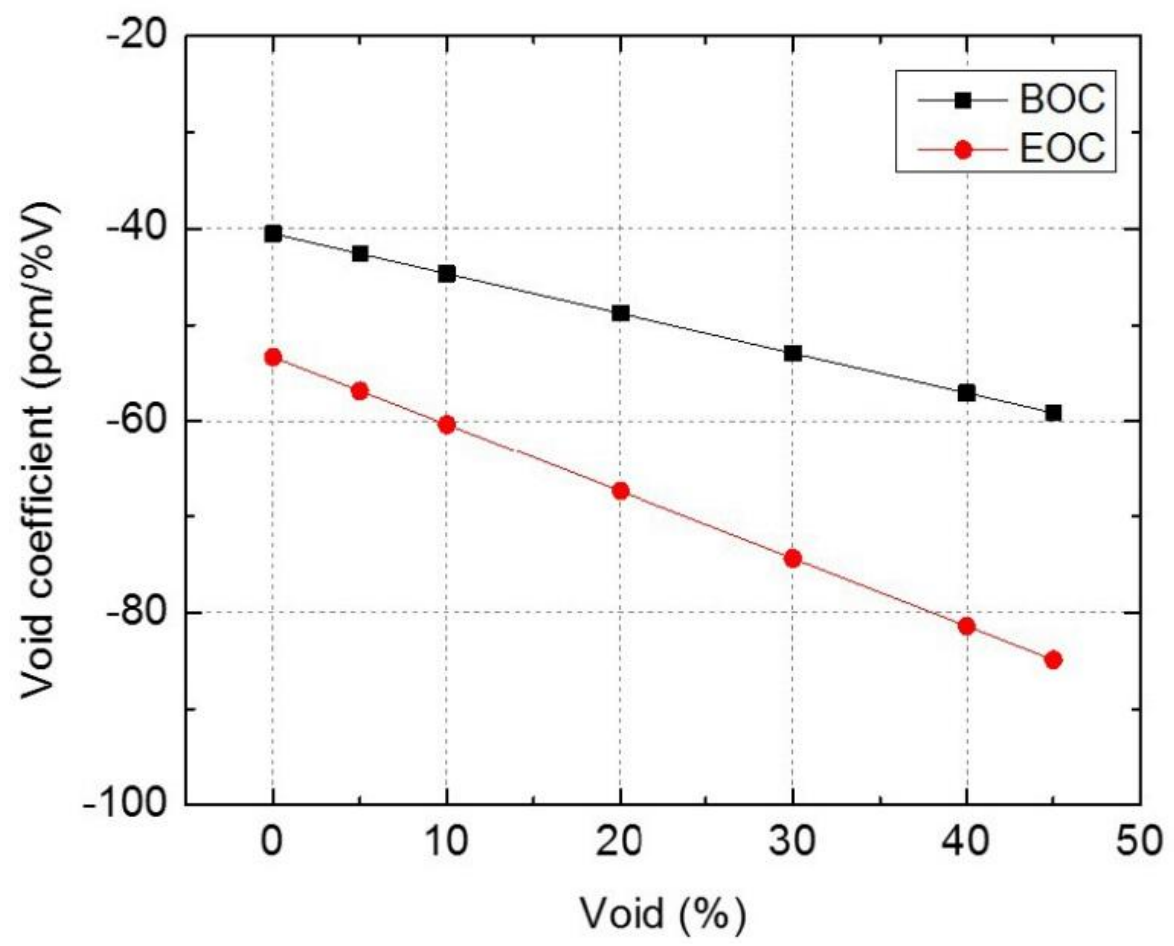


Fig. 15. Void coefficient as a function of coolant void fraction at BOC and EOC.

To ensure safe reactor operations, the reactor should be shut down from the most reactive state during the life cycle, with a sufficient margin. For a conservative measure of cold shutdown margin, the "stuck-rod criterion" was used. This method involves the calculation of the total control blade reactivity worth, excluding the most reactive control blade (stuck out of core). The shutdown margin was evaluated at the cold and xenon-free reactor condition at peak excess reactivity and EOC. At EOC, the reactivity feedback coefficients are most negative. However, the most limiting SDM margin was found to be at peak excess reactivity. The control reactivity balance is summarized in Table 7. The result shows that NMR-50 reactor design provides a sufficient cold shutdown margin.

Table 7

Control reactivity balance and SDM at most reactive state.

\begin{tabular}{ll}
\hline & Value $(\% \rho)$ \\
\hline Temperature and Power Defect & 9.148 \\
Equilibrium Xe/Sm to HFP $^{\mathrm{a}}$ & 2.070 \\
HFP to HZP $^{\mathrm{b}}$ & 5.054 \\
HZP to CZP & \\
Excess Reactivity & 2.023 \\
Control Blade & 10.170 \\
SDM & 21.091 \\
${ }^{\mathrm{a}}$ Hot full power; ${ }^{\mathrm{b}}$ hot zero power; ${ }^{\mathrm{c}}$ cold zero power
\end{tabular}

\subsection{Vulnerability to Xenon oscillation}

In the current LWR community, xenon oscillation phenomenon is most significant in PWRs due to the large height of the reactor core that allows for little flux coupling between regions, thus enhancing the vulnerability of a spatial power oscillation. This phenomenon becomes less significant in BWR's due to the large void reactivity effect. It provides an abundance of damping to suppress power oscillations, and hence a high xenon stability characteristic (Oka and Suzuki, 2013). Since xenon induced power oscillations become less important in smaller size core, NMR-50 could exhibit an enhanced xenon stability characteristic compared to current BWRs (Worrall, 2015). To provide a constructive analysis, the magnitude of xenon induced reactivity worth was calculated for both NMR-50 and a conventional BWR, Oskarshamn-2 (O-2), in Sweden. The reactor condition was considered at around one fourth of the cycle, which is when the burnable absorber is burnt out leading to the largest axial power peaking factor and relative power.

The upper and lower limit of AO during the NMR-50 cycle of operation does not violate the standards set in the LWR industry. In practice, AO limits are bound between $-18 \%$ to $2 \%$ at $100 \%$ full power. 
The 3-D spatial xenon concentration was computed using PARCS at equilibrium state. Axial thermal neutron flux accompanied by the Xe-135 concentration for both NMR-50 and O-2 is shown in Fig. 16. In addition, the xenon induced reactivity worth for both NMR-50 and O-2 is shown in Fig. 17. This study is not a transient analysis, but it gives a relative evaluation of xenon induced reactivity worth in NMR-50.

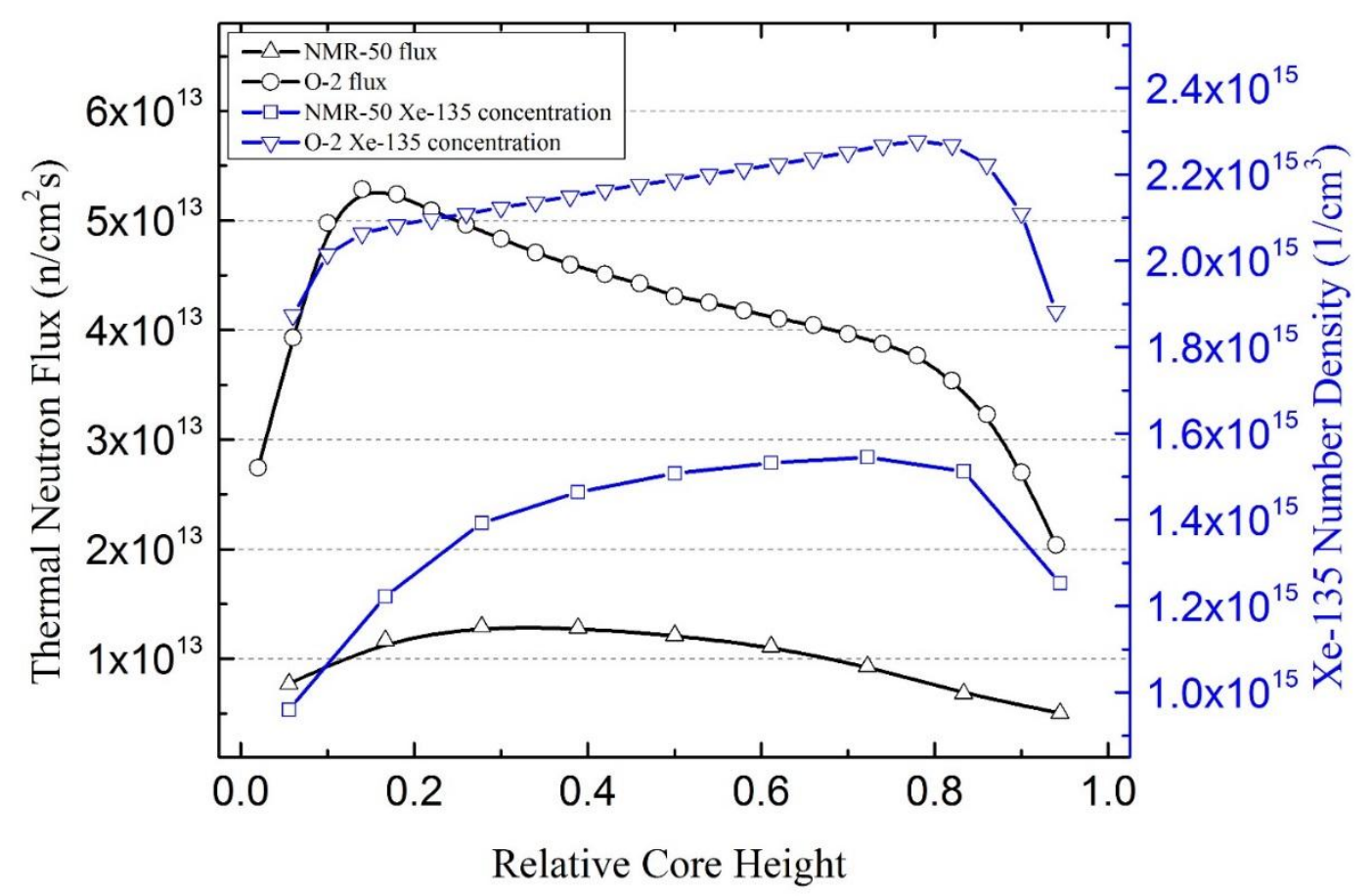

Fig. 16. Axial distributions of thermal neutron flux and xenon concentration in NMR-50 and Oskarshamn-2 at one fourth of cycle. 


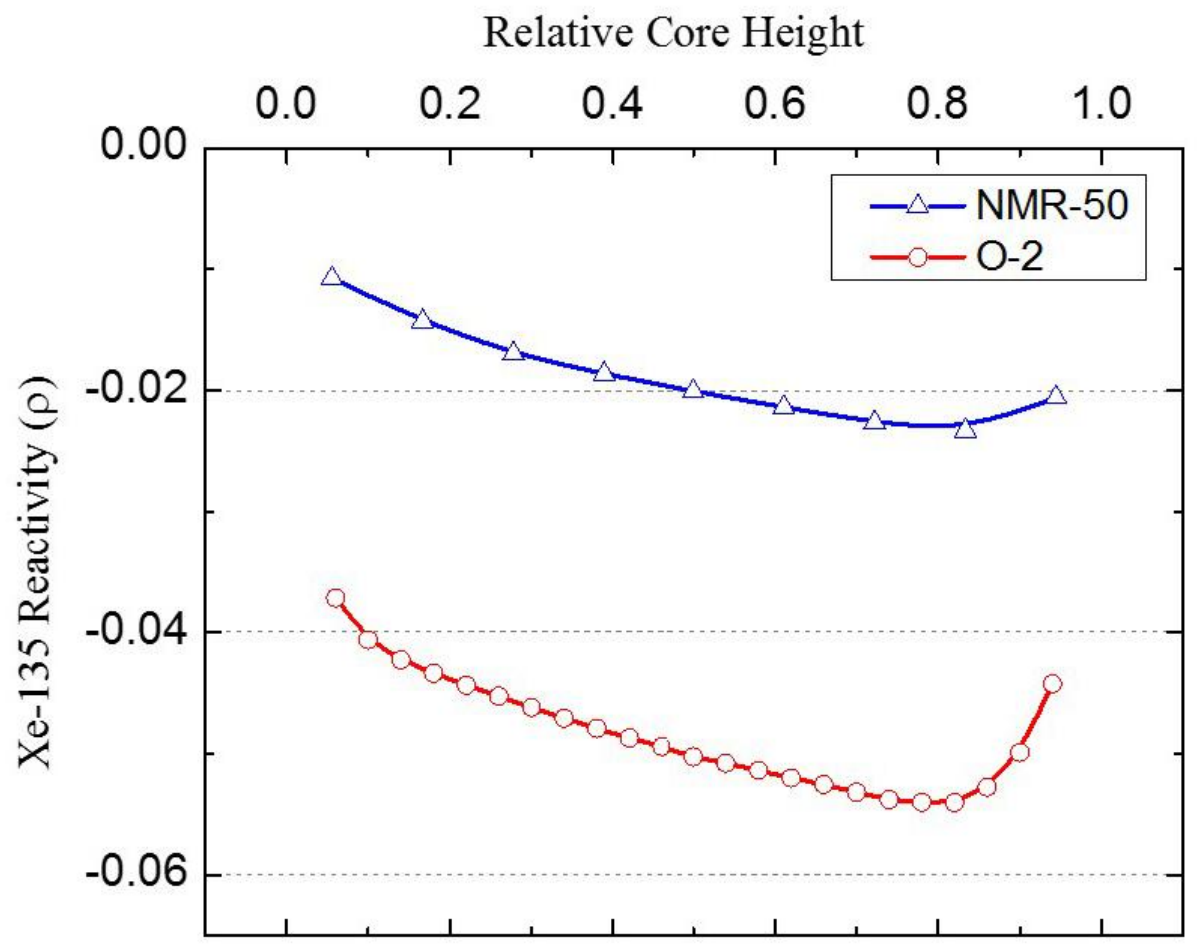

Fig. 17. Axial distribution of xenon-135 induced reactivity.

Key take out point is the relative magnitude of xenon induced reactivity worth in NMR-50 compared to conventional BWR. Around two fold reduction in xenon reactivity worth in NMR50 compared to $\mathrm{O}-2$, is observed. This reduction in reactivity worth owes to the significant reduction in thermal flux, by a factor of four.

\subsection{Potential consequences of long life core on structural material}

With almost half a century of operational experience in BWRs, the main consideration of increased fuel cycle length is channel distortions (Garzarolli et al., 2011). The BWRs channel box may experience dimensional deformation that could induce control blade friction and even, in the worst case, prevent control blade insertion. There are three major distortion phenomena: bulging, bowing, and twisting. It was found that channel bowing is the major concern and is mainly due to what is so-called shadow corrosion-induced. The shadow corrosion-induced bow is enhanced by the insertion of control blade due to the galvanic effect of two dissimilar metals. Therefore, the differential hydrogen content of the two channel faces leads to channel bow; due to the larger specific volume of $\mathrm{ZrH}$ compared of zircaloy-2 (Bradley and Sabol, 1996).

Material irradiation growth is strongly dependent on the fast neutron fluence. With NMR-50 operating at low power density and with a relatively lower neutron flux, the fast neutron fluence on the channel box at EOC is significantly lower than current BWRs. Research showed that significant growth was observed at fast fluence greater than $1 \times 10^{22} \mathrm{n} / \mathrm{cm}^{2}$. Moreover, from extensive plant data regarding measured channel bow as a function of burnup, results showed a 
threshold type phenomenon where channel bow was noticed at burnup levels around $40 \mathrm{GWd} / \mathrm{tU}$ and greater (Garzarolli et al., 2011). Therefore, realizing that NMR-50 EOC peak fast neutron fluence is $8.8 \times 10^{21} \mathrm{n} / \mathrm{cm}^{2}$ and that average and maximum cycle burnup is around 33 and 40 $\mathrm{GWd} / \mathrm{tU}$, it can be concluded that NMR-50 could exhibit less of a concern over its 10-year cycle length. Moreover, utilizing the control cell core approach, control blades are not inserted in center of core, hence, reducing the possibility of shadow corrosion-induced bowing. 


\section{Conclusions}

Through a systematic step-wise optimization approach, an optimum fuel assembly design was developed for the NMR-50. This fuel assembly design with an average fuel enrichment of $4.61 \mathrm{wt} \%$ yields a 10.2-year cycle length. Seven gadolinia fuel rods within an assembly were chosen with an average Gd enrichment of $6.17 \mathrm{wt} \%$. When compared to previous NMR-50 design (Wu et al., 2015), the fissile mass loading and total enriched Gd amount was reduced by $6 \%$ and $40 \%$, respectively, while maintaining both the 10-year cycle length and the required hold down of excess reactivity. The MCPR and MFLPD during the cycle are 1.99 and $18.25 \mathrm{~kW} / \mathrm{m}$, respectively, showing that the thermal design constraints are satisfied with large margins. The reactivity feedback coefficients were sufficiently negative, and a sufficient cold shutdown margin of $1.7 \% \rho$ was provided. The possibility of xenon oscillation is always present, but with a larger negative $\mathrm{VC}$, a small size core, and a low operating thermal neutron flux, the induced power oscillation is heavily damped. This could provide NMR-50 with enhanced xenon stability characteristics. The reduced power density and increased leakage allow for a lower EOC fast neutron fluence on the structural materials as well as lower cycle burnup. NMR-50 peak fast neutron fluence at the channel box is $8.8 \times 10^{21} \mathrm{n} / \mathrm{cm}^{2}$ and maximum cycle burnup is 40 $\mathrm{GWd} / \mathrm{tU}$. Thus, from extensive plant data records, channel distortion is not a major concern. Future work related to NMR-50 design includes multiple sectors. Due to the reduced power density and increased thermal safety margins, one could utilize reduced moderation more effectively that could reduce initial fissile inventory for enhanced cycle length. 


\section{Acknowledgement}

This research is being performed using funding received from the DOE Office of Nuclear Energy's Nuclear Energy University Programs.

The first author would like to thank Dr. Tongkyu Park from FNC Technology, and currently a visiting scholar at the Department of Nuclear Engineering at Purdue University, for providing tremendous assistance on simulated annealing based optimization algorithm. 


\section{References}

Aarts, E., Korst, J., 1989. Simulated Annealing and Boltzmann Machines. John Wiley \& Sons.

Abarca, A., Barrachina, T., Miró, R., Verdú, G., 2011. Instability Analysis in Peach Bottom NPP Using a Whole Core Thermal hydraulic-Neutronic Model with RELAP5 / PARCS v2. Nucl. Sci. Technol. 2, 130-138.

ABWR Design Control Document, 1997. . GE Nuclear Energy.

Agung, A., Bánáti, J., Stålek, M., Demazière, C., 2013. Validation of PARCS/RELAP5 coupled codes against a load rejection transient at the Ringhals-3 NPP. Nucl. Eng. Des. 257, 31-44. doi:10.1016/j.nucengdes.2012.12.023

Bradley, E.R., Sabol, G.P. (Eds.), 1996. Zirconium in the Nuclear Industry: Eleventh International Symposium, Issue 1295. ASTM International.

Downar, T., Barber, D.A., Joo, H.G., Ulses, A.P., 2002. PARCS Purdue Advanced Reactor Core Simulator, in: Proceedings of the International Conference on the New Frontiers of Nuclear Technology (PHYSOR '02). Seoul, Korea.

Downar, T., Xu, Y., Seker, V., Hudson, N., 2010. PARCS v3.0 - U.S. NRC Core Neutronics Simulator. User Manual UM-NERS-09-0001. University of Michigan, Ann Arbor, MI.

Ekberg, K., Forssén, B.-H., Knott, D., Umbarger, J., Edenius, M., 1995. CASMO-4: A Fuel Assembly Burnup Program. User's Manual Studsvik/SOA-95/1. Studsvik Scandpower.

Garzarolli, F., Adamson, R., Strasser, A., Rudling, P., 2011. BWR Fuel Channel Distortion, ANT International. Molnlycke, Sweden.

Grgić, D., Benčik, V., Šadek, S., 2013. Coupled code calculation of rod withdrawal at power accident. Nucl. Eng. Des. 261, 285-305. doi:10.1016/j.nucengdes.2012.10.026

Hench, J.E., Gillis, J.C., (1981). Correlation of Critical Heat Flux Data for Application to Boiling Water Reactor Conditions. EPRI-NP-1898.

IAEA, 2012. Status of Small and Medium Sized Reactor Designs. URL https://www.iaea.org/NuclearPower/Downloadable/SMR/files/smr-status-sep-2012.pdf (accessed 7.9.15). 
Ishii, M., Hibiki, T., Yang, W.S., Schlegel, J.P., Wu, Z., Shi, S., Lin, Y.C., Eoh, J.H., Brooks, C.S., Clark, C., 2013. Investigation of Natural Circulation Instability and Transients in Passively Safe Small Modular Reactors. PU/NE-13-10.

Ishii, M., Shi, S., Yang, W.S., Wu, Z., Rassame, S., Liu, Y., 2015. Novel modular natural circulation BWR design and safety evaluation. Ann. Nucl. Energy 85, 220-227. doi:10.1016/j.anucene.2015.05.009

Kirkpatrick, S., Gelatt, C.D., Vecchi, M.P., 1983. Optimization by Simulated Annealing. Science 220, 671-680. doi:10.1126/science.220.4598.671

Kozlowski, T., Miller, R.M., Downar, T.J., Joo, H.G., 2004. Consistent Comparison of the Codes RELAP5/PARCS and TRAC-M/PARCS for the OECD MSLB Coupled Code Benchmark. Nucl. Technol. 146, 15-28.

Metropolis, N., Rosenbluth, A.W., Rosenbluth, M.N., Teller, A.H., Teller, E., 1953. Equation of State Calculations by Fast Computing Machines. J. Chem. Phys. 21, 1087. doi:10.1063/1.1699114

Odeh, F., Yang, W.S., 2015. A Systematic Core Design Optimization of the Purdue Novel Modular Reactor (NMR-50). Trans. Am. Nucl. Soc. 113, 1053-1056.

Oka, Y., 2010. Nuclear Reactor Design. Tokyo: Springer. doi:10.1007/978-4-431-54898-0

Oka, Y., Suzuki, K., 2013. Nuclear Reactor Kinetics and Plant Control. doi:10.1007/978-4-43154195-0

Renier, J.-P.A., Grossbeck, M.L., 2001. Development of Improved Burnable Poisons for Commercial Nuclear Power Reactors. Oakridge, TN.

Tinkler, D.R., Downar, T.J., 2003. The neutronics design and analysis of a 200-MW(electric) simplified boiling water reactor core. Nucl. Technol. 142, 230-242.

Tong, L.S., 1988. Principles of design improvement for light water reactors. Hemisphere Publishing, New York, USA.

Turinsky, P.J., 2010. Core Isotopic Depletion and Fuel Management, in: Handbook of Nuclear Engineering. Springer, New York, pp. 1241-1312. doi:10.1007/978-1-4419-9572-8

U.S. NRC, 2006. RELAP5/MOD3.3 Code Manual, vol. 1-8, NRC Report NUREG/CR5535/Rev 1. U.S. NRC. 
Worrall, a., 2015. Core and fuel technologies in integral pressurized-water reactors (iPWRs), Handbook of Small Modular Nuclear Reactors. Woodhead Publishing Limited. doi:10.1533/9780857098535.2.79

Wu, Z., Yang, W.S., Shi, S., Ishii, M., 2015. A Core Design Study for a Small Modular Boiling Water Reactor with Long-Life Core. Nucl. Technol., accepted for publication.

Wu, Z., Yang, W.S., Shi, S., Ishii, M., 2015. Core Design Studies for a BWR-Based Small Modular Reactor with Long-Life Core. Trans. Am. Nucl. Soc. 112, 5-8.

Xu, Y., Downar, T., 2012. GenPMAXS-V6 Code for Generating the PARCS Cross Section Interface File PMAXS. 